\title{
From Nanocellulose to Wood Particles: A Review of Particle Size vs. the Properties of Plastic Composites Reinforced with Cellulose-based Entities
}

\begin{abstract}
Martin A. Hubbe ${ }^{\mathrm{a}, *}$ and Warren Grigsby ${ }^{\mathrm{b}}$
This review article considers published evidence regarding effects of particle size on mechanical properties of plastic matrix materials filled with cellulose-based reinforcements. Cellulosic or wood-based reinforcements in plastic matrices can contribute to higher modulus, lower density, and less tendency to sag in comparison with the matrix phase by itself, while still allowing the resulting material to be cut or milled. Although cellulosic materials are generally too hydrophilic to adhere well to common thermoplastic materials such as polyethylene, such deficiencies can be overcome by use of compatibilizers, e.g. polyethylene-maleic anhydride. Recently many researchers have evaluated nanocellulose in plastic composites. The higher surface areas of nanocellulose generally imply a higher cost of compatibilizer to achieve good interfacial adhesion. This review first examines results of a large number of studies all involving highdensity polyethylene as the matrix. Then, to get a more detailed mechanistic view, studies are considered that compare different particle sizes of cellulose-based reinforcements within the same conditions of preparation of composites prepared with various matrix polymers. To summarize the findings, there does not appear to be any consistent and dependable advantage of using nano-sized cellulosic reinforcements when trying to achieve higher values of composite strength or modulus.
\end{abstract}

Keywords: Wood-plastic composites; Cellulose-based reinforcements; Size of filler particles; Nanocomposites; Tensile strength and modulus

Contact information: a: North Carolina State University, Department of Forest Biomaterials, Box 8005, Raleigh, NC 27695-8005 USA; b: Scion, Rotorua 3010, New Zealand;

*Corresponding author: hubbe@ncsu.edu

\section{Contents}

Introduction .............. 2031

Theoretical background ......... 2032

Two phases better than one . . . . 2032

Mechanisms of failure ........ 2033

Positive aspects of nanoparticles 2034

Negative aspects of nanoparticles 2035

Positive aspects of large particles 2035

Concerns about large particles . . 2037

Expectations based on modeling 2038

Experimental findings . . . . . . . 2038

Strategy: Big picture, then details 2038

Part A: Studies with HDPE matrix 2040

Tensile strength . . . . . . . 2041

Tensile modulus . . . . . . . 2042

Tensile elongation ........ 2043

Flexural strength . . . . . . . . 2043
Flexural modulus . . . . . 2045

HDPE \& particle size . . . 2045

Part B: Comparing sizes ... 2048

Polypropylene matrix . . . 2048

Polyamides . . . . . . . 2049

Poly-(lactic acid) . . . . . 2050

Other polyesters . . . . . 2051

Polyurethanes ....... 2052

Poly-(ethylene oxide) . . . 2052

Acrylics .......... 2052

Epoxies .......... 2053

Phenol-formaldehyde ... 2053

Poly-(vinyl alcohol) ..... 2054

Starch and related .... 2055

Disclaimers .......... 2055

Concluding statements ...... 2057 


\section{INTRODUCTION}

There is strong interest, both in academic research and within industry, relating to the incorporation of cellulose-based reinforcements during the preparation of plastic composites to modify or enhance their performance. Such composites have the potential to be more weather-tolerant than wood in exterior applications (Wolcott et al. 1999). They also have the potential to be stronger than the base plastic in certain respects, such as the flexural modulus that determines the resistance to bending (Aji et al. 2011; Aggarwal et al. 2013). At the same time, the usage of under-utilized cellulose-based resources in composites has favorable environmental implications (Wolcott et al. 1999), including the sequestration of carbon (Bolin and Smith 2011) and the relatively low environmental impact of wood-based and cellulose-fiber-based products compared to some other commodities (Xu et al. 2008; Sathre and O'Connor 2010).

Developments in the field of cellulose-reinforced plastic composites have been reviewed (Thakur and Thakur 2014; Borah et al. 2016; Mohit and Selvan 2018). Biobased composites, in which the matrix as well as the reinforcements are derived from plant materials, including biothermoset resins, have received increasing attention (Reddy et al. 2010; Crosky et al. 2014; Chan et al. 2018; Pizzi 2018). Cellulose-based fibers (Lee et al. 2014; Ramamoorthy et al. 2015) can be obtained not only from wood, but also from plant sources such as cotton and flax. They also can be obtained from bacterial exudates, as well as animal sources in the case of tunicate nanocrystals. The aforementioned materials often can provide more eco-friendly alternatives by displacing the usage of petroleum-based, non-biodegradable plastics.

In the last two decades there has been intense interest, especially among academic scientists, in applications of nanomaterials (Berube 2006). It has been claimed, for instance, that nano-sized reinforcements, including nanocellulose, have the potential to achieve greater increases in composite strength in comparison to ordinary-sized reinforcements (Fu et al. 2008; Tanpichai and Wootthikanokkhan 2018). Also, nanocellulose appears to be able to increase the stiffness and other strength properties of plastic composites when present at relatively low levels (Puglia et al. 2015; Fortunati et al. 2016; Saikia et al. 2019).

On the other hand, nanomaterials are almost always more expensive than the larger materials from which they are produced. In the case of nanocellulose, two of the largest components of cost are often energy and chemicals (Delgado-Aguilar et al. 2015), and the balance between these two categories will depend on the type of nanocellulose being considered. When cellulosic materials are intended for use in plastic composites, one of the key costs categories to bear in mind is that of a compatibilizing treatment. Compatibilizers can involve either surface treatment of a cellulosic reinforcing material before its use or addition of a coupling agent to the matrix polymer before extrusion and compounding. As will become strikingly evident from literature to be considered in this review, compatibilizing treatments can play an essential role, especially in the case of nonpolar matrix materials such as polyethylene (George et al. 2001; Belgacem and Gandini 2005; Kumar et al. 2011). Accordingly, the very high surface area of nanomaterials necessarily inflates the associated costs.

The idea for the present review article first started as a matter of curiosity: Given that it often takes more energy and effort to prepare composites with smaller cellulosebased elements, the question can be asked as to what one can expect to get in return. An initial doubt about whether there is a benefit of using nanocellulose for plastic composites 
was expressed in an earlier review article (Hubbe 2017), but that publication presented little supporting evidence. A few examples from the literature pertaining to the topic were cited in a more recent conference presentation, titled "Think big: The case against relying just on nanocellulose to reinforce plastic composites" (Hubbe 2018). The present review article follows up with a more extensive examination of the published literature, with particular emphasis on effects of particle size in cellulose-based reinforcement of highdensity polyethylene (HDPE) composites. This work also builds upon the important synthesis of information achieved in earlier review articles. Selected review articles, and their themes, are given in Table 1.

Table 1. Review Articles Dealing with Cellulose and Nanocellulose-based Plastic Composites

\begin{tabular}{|l|l|}
\hline Main Themes Discussed & References \\
\hline Technology review of wood-polymer composites & Wolcott et al. 1999 \\
\hline Interfaces and natural fiber-plastic composites & George et al. 2001 \\
\hline Cellulose surface modification for adhesion to matrix & Belcacem \& Gandini 2005 \\
\hline Cellulose-based nanocomposites & Hubbe et al. 2008 \\
\hline Cellulose fibril- and whisker-polymer nanocomposites & Gindl 2009 \\
\hline Cellulose nanofibers and nanocomposites & Eichhorn et al. 2010 \\
\hline Bast fibers and their composites & Summerscales et al. 2010 \\
\hline Wood flour-plastic composites & Kumar et al. 2011 \\
\hline Cellulose nanomaterials and nanocomposites & Moon et al. 2011 \\
\hline Use of recycled plastics in wood-plastic composites & Najafi 2013 \\
\hline Plastic reinforced with cellulose nanocrystals & Peresin et al. 2013 \\
\hline Numerical simulation of wood-plastic composites extrusion & Yuan \& Chen 2013 \\
\hline Extruded and solvent-casted cellulosic composites & Forunati et al. 2016 \\
\hline Surface treatments of natural fibers for composites & Verma \& Jain 2017 \\
\hline Fracture toughness and impact strength & Al-Maharma \& Sendur 2019 \\
\hline Flax fiber reinforced plastic composites & Ramesh 2019 \\
\hline
\end{tabular}

\section{THEORETICAL BACKGROUND}

\section{Why Two Phases Can Be Better than One}

The motivating principle of composites is to achieve properties that cannot be reached using either of the constituent materials by itself (Wolcott et al. 1999). Often the goal is to achieve higher strength attributes, taking advantage of an inherent higher modulus of elasticity of a reinforcing (filler) material. As noted by Kalaprasad et al. (1997), the strength properties of plastic composites reinforced by relatively short cellulosic fibers generally depend on the fiber loading, any orientation of the fibers, the lengths of the fibers, and the strength of adhesion between the fibers and the plastic matrix. The cited work discusses the main theories that have been developed to account for mechanical properties of composites. In general, the models are able to explain the main features of experimental findings. Another common objective, which lies outside of the scope of the present review, would be to lower the cost of the resulting product by filling the plastic with a less expensive material, while still meeting the requirements for the product (Lightsey et al. 1977; Toupe et al. 2014). 


\section{Mechanisms of Failure}

The strength of a composite is generally judged by how it deforms and how it ultimately fails when subjected to forces and stresses under defined geometries and conditions (Jenkins 1998; Campilho 2016). In particular, both the tensile modulus and the shear modulus can be evaluated by determining the ratio of stress to strain under conditions that are usually selected to be within a linear range, i.e. stress levels that do not cause damage. By contrast, the term "strength" is often applied to tests that evaluate the maximum tensile stress or flexural stress leading to breakage ( $\mathrm{Fu}$ et al. 2008; $\mathrm{Ku}$ et al. 2011; Dhakal et al. 2015). These quantities, along with the strain associated with tensile breakage, will be a main focus of this review when considering experimental findings.

Breakage represents a dramatic form of failure, and tensile breakage is the simplest case to consider. In brief, tensile breakage can involve either failure of the reinforcing elements (e.g. cellulosic fibers or nanocellulose), breakage of the matrix material, debonding between the matrix and the reinforcement, or debonding within agglomerates of the reinforcing elements. Once a crack is initiated, the process often proceeds in an outof-control manner, following paths of weakness in the structure. Some references to each of the mentioned events, related to cellulose-based plastic composites, are given in Table 2. None of the cited articles report specific evidence of failure initiated by fracture within a plastic matrix phase, except when the plastic by itself was being evaluated as a control.

Table 2. Mechanistic Evidence from Various Studies of Cellulose-based Plastic Composites

\begin{tabular}{|l|l|}
\hline Type of Mechanistic Evidence & Selected References \\
\hline Fracture of the cellulose-based reinforcement & $\begin{array}{l}\text { Summerscales et al. 2010; Alavi et al. 2013; } \\
\text { Fonseca-Valero et al. 2015; He et al. 2016 }\end{array}$ \\
\hline Debonding between the matrix \& reinforcement & $\begin{array}{l}\text { Alavi et al. 2013; He et al. 2016; Mu et al. } \\
\text { 2018; Simao et al. 2019 }\end{array}$ \\
\hline $\begin{array}{l}\text { Debonding within agglomerates of cellulose- } \\
\text { based reinforcements }\end{array}$ & $\begin{array}{l}\text { Ismail \& Shafiq 2016; Lewandowska et al. } \\
\text { 2018; DiLoreto et al. 2019 }\end{array}$ \\
\hline $\begin{array}{l}\text { Large increases in strength when using } \\
\text { compatibilizing agents }\end{array}$ & $\begin{array}{l}\text { George et al. 2001; Fu et al. 2008; Farsi } \\
\text { 2012; Alavi et al. 2013; Durmus et al. 2019 }\end{array}$ \\
\hline
\end{tabular}

The quality of bonding between a cellulosic surface and a plastic matrix material tends to be of critical importance. Gaugler et al. (2019) recently showed that such bonds can be evaluated quickly and precisely by preparing sandwich-type composites. Specimens consisting of wood in combination with various thermopolymers were prepared over a range of temperatures, followed by in situ mechanical testing. The polarity of the plastic was found to be important. Fluorescence microscopy visualization of laminate composites bond lines revealed the ingress of thermopolymer into the pores of the adjacent wood phase, which was found to be temperature-dependent. The degree of ingress of polymer into the pores of the wood was indicative of effective adhesion between the phases (Luedtke et al. 2019; Grigsby et al. 2019).

\section{Aspect ratio issues}

The aspect ratio of a particle can be defined as the quotient of its length divided by its thickness. The relationship between aspect ratio and the strengths of composite materials has been discussed in review articles (Tucker and Liang 1999; Puglia et al. 2015; Fortunati et al. 2016). A more effective transfer of stress from the matrix to the fiber is 
expected when the aspect ratio is higher (Frone et al. 2011). Stark and Rowlands (2003) attributed greater reinforcing effects of wood fibers in comparison to wood flour in polypropylene composites to the higher aspect ratio of the fibers. It has been found that the high aspect ratio in addition to the high surface area of nanofibers from woody material usually make a positive contribution to strength in the composites (Fortunati et al. 2016). $\mathrm{Xu}$ et al. (2013) used similar reasoning to account for a greater contribution to strength from nanofibrillated cellulose in comparison to cellulose nanocrystals. Similarly, Gozdecki et al. (2015) used aspect ratio to explain a set of results in which larger wood particles made a greater contribution to the strength of composites. Khonsari et al. (2015) attributed a greater contribution of ground shavings of wood flakes to flexural modulus to their relatively high aspect ratio in comparison to wood flour. Sapkota et al. (2017) found that the effects of aspect ratio on composite properties were strongly influenced by the contribution of those particles having the highest aspect ratio.

Though higher aspect ratio often decreases the probability that the reinforcement will detach from the matrix during breakage, one can also generally expect a greater extent of agglomeration in the course of preparing the composite (Hubbe et al. 2017). Furthermore, reinforcements that are long relative to their diameter or thickness will generally increase the viscosity of the mixture, making it more difficult to process. During high-shear processing, as with twin-screw extrusion, reinforcement particles having a high aspect ratio are often broken, yielding a mixture that has a much lower distribution of aspect ratios (Bouafif et al. 2010; Thumm and Dickson 2013; Soccalingame et al. 2015). Li et al. (2014) reported a case in which addition of a dispersion agent to HDPE succeeded in getting a better mixing of cotton nanofibers, while at the same time resulting in a greater degree of shortening during processing. Another important factor is the deviation from rod-like shape, even in cases where cellulose-based particles might initially appear straight. Newman et al. (2014) showed that cellulosic fibers tend to develop curves and kinks during injection molding, whereas glass fibers tend to remain rod-like. As a consequence, cellulose-based fibers, when used as fillers in injection molding of composites, would not be expected to match the theoretically predicted modulus values. Rather, the theoretical models tend to over-estimate the strength of cellulose fiber-reinforced composites (Newman et al. 2014). As will be seen in later sections of this article, composites prepared with nanofibrillated cellulose sometimes have been reported to achieve relatively high gains in mechanical properties, compared to similar levels of other reinforcing particles. The very high aspect ratio of nanofibrillated cellulose is expected to have been an important factor to explain such results.

\section{Positive Aspects of Using Cellulose-based Nanoparticles}

If indeed there are advantages to using smaller, even nano-sized reinforcing elements in a composite, what could be the theoretical basis used to explain or predict such benefits? One such theory involves effects of the reinforcements on the degree of crystallinity of the matrix material when it cools from a melt. Various studies have reported evidence for increased crystallinity in the presence of nano-sized cellulose-based reinforcements (Mokhena and Luyt 2014; Boran et al. 2016; Sun 2018; Pereira et al. 2019; Peric et al. 2019; Wang et al. 2019a). Such effects would be expected to be related to the surface area of the reinforcements, which is much higher in the case of nanomaterials. Inducing additional crystallinity within the plastic phase generally provides a higher elastic modulus, leading to greater stiffness (Krishnaiah et al. 2017). 
Some potential advantages of using very small reinforcing particles fall outside of mechanical properties, which is the primary focus of this review. For example, the tiniest of cellulosic particles, the cellulose nanocrystals (Samir et al. 2005; Eichhorn et al. 2010; Moon et al. 2011), have a very high level of crystallinity (e.g. 54-88\%, Moon et al. 2011), and this could be an advantage sometimes in terms of structural stability or insensitivity to moisture (Tyagi et al. 2019). In addition, some potential applications such as 3D printing may require thermoplastic formulations to pass through very small openings (Siqueria et al. 2017). Certain nanocomposites can achieve very high levels of transparency, which may be beneficial in some applications (Eichhorn et al. 2010; Soykeabkaew et al. 2012; Xu et al. 2013; Nair et al. 2019; Saikia et al. 2019). While dependent on the formulation, highly transparent composites can be prepared when using nanocellulose particles for reinforcement (Nair 2019).

\section{Negative Aspects of Using Cellulose-based Nanoparticles}

Some potential downsides of using nanomaterials for reinforcement of plastic composites were already detailed in the Introduction. For example, nanocellulose products - and even fine-ground particles or flours - tend to involve higher energy input, along with higher costs of preparation (de Assis et al. 2017). If there is a need to treat the surfaces or to add a compatibilizing agent to the matrix, then intuitively the required amounts of these agents will tend to be higher when the surface area of the reinforcing particles is increased, as in the case of nanoparticles (Hubbe 2017). In support of this concept, Tarrés et al. (2019) observed that specific amounts of coupling agent were needed in polypropylene systems reinforced with henequen strands of different size in order to achieve maximum strength. There are also some practical challenges inherent in working with particles that are too small to be collected easily by filtration. Thus, centrifugation is widely used to increase the solids content of nanocellulose suspensions (Wang et al. 2012). It also can be a challenge to monitor and control the properties of cellulose nanoparticles, especially in the case of highly fibrillated cellulose products, due to their tiny dimensions and complex structure (Lavoine et al. 2012; Kangas et al. 2014).

\section{Positive Aspects of Using Macroscopic Cellulose-based Reinforcements}

When considering wood as a material for construction, it is important to keep in view the full range of dimensions, starting from molecular, proceeding through nano-range structural arrangements of cellulose, hemicelluloses, and lignin within small sections of cell walls, then proceeding to the layered arrangements of fibrils within fibers, and then to the manner in which fibers are bonded together to constitute wood. These essential issues are addressed in textbooks of the field (Lewin and Goldstein 1991; Kettunen 2006). At each scale of observation, the structural components of wood are arranged in a welloptimized pattern that is capable of transferring stresses and strains in an efficient manner, thus achieving a remarkable combination of material strength, stiffness, and toughness. For example, the microfibril angles in the different sublayers of a fiber cell wall are arranged to achieve a favorable tensile modulus response, while also protecting against the collapse or bulging of an individual fiber (Fig. 1). All of these parts are already essentially "glued together" in their natural state. This being the case, it would seem logical to use the largest practical pieces of the original wood as the starting point for preparation of a composite material. 


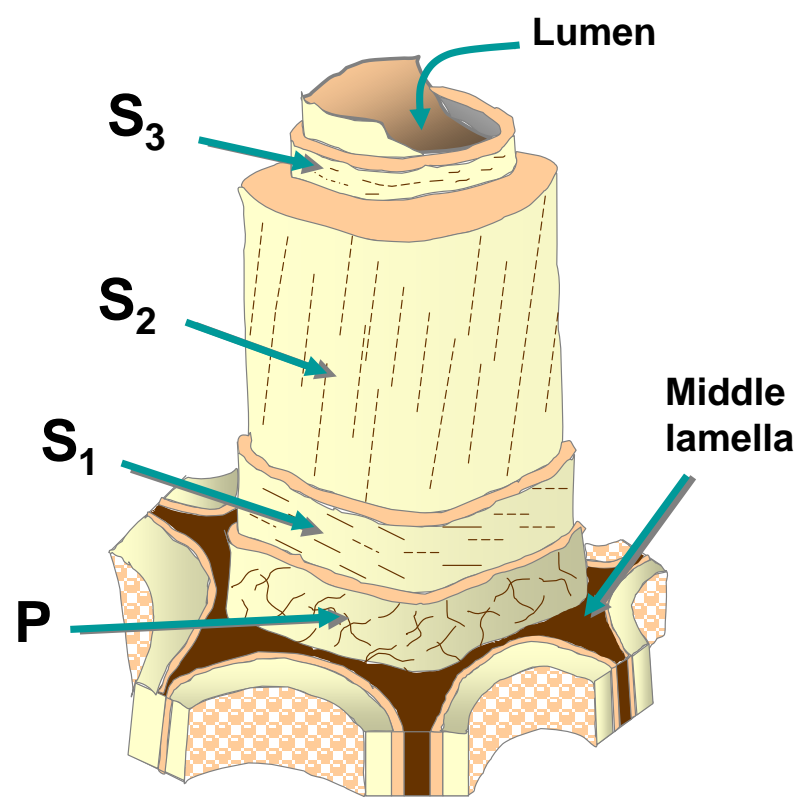

Fig. 1. Illustration of the layered structure of a typical fiber within wood. Note that "P" stands for "primary" and that "S" followed by a number indicates parts of the "secondary" layer. Lines drawn on the $P, S_{1}, S_{2}$, and $S_{3}$ layers indicate the predominant orientations (or lack thereof) of the microfibrils.

Relatively large pieces of cellulosic material, including wood particles and fibers, have a much lower outer surface area per unit mass in comparison to nanocellulose. As an extreme example, a cellulose nanocrystal has a specific surface area of ca. $500 \mathrm{~m}^{2} / \mathrm{g}$, whereas dried kraft fibers have surface areas of the order of magnitude of only $1 \mathrm{~m}^{2} / \mathrm{g}$ (see sample calculations in the Appendix). The much lower specific surface area of relatively large fibers or particles makes it much more reasonable to consider strategies that involve surface modification. As shown in review articles, the hydroxyl groups at cellulosic surfaces provide opportunities for various chemical modifications, leading to better adhesion to a hydrophobic matrix (Belcacem and Gandini 2005; Hubbe et al. 2015; Verma and Jain 2017).

Table 3 lists some of the major fiber surface modification chemistries that have been demonstrated for improving adhesion within a plastic matrix. The first two categories considered in the table involve chemical derivatization of the cellulosic surfaces before preparation of the composite. By contrast, the third and fourth categories (identified with an asterisk) involve addition of a compatibilizing agent to the plastic material before compounding or hot-pressing. The two main compatibilizing agents that are used this way, especially with polyethylene and related matrix types, are maleic anhydride polyethylene (MAPE) and maleic anhydride polypropylene (MAPP). In these two cases, the covalent reactions with the cellulosic surfaces generally take place only after the reinforcing material has been added to the polymer, either as a melt or as material to be heated during an extrusion process. An exception to this rule was the work of Zhang et al. (2019a). In that study the surfaces of cellulosic nanocrystals (CNC) were individually modified with MAPP. Such treatment led to large improvements in the strength of composites formed with an acrylic copolymer. 
Table 3. Surface Modification Chemistries Shown to be Effective to Improve Adhesion of Cellulose-based Reinforcements within Various Plastic Matrix Types

\begin{tabular}{|l|l|}
\hline $\begin{array}{l}\text { Type of Chemical } \\
\text { Treatment }\end{array}$ & References \\
\hline $\begin{array}{l}\text { Silane (trimethoxy- } \\
\text { silane compounds) }\end{array}$ & $\begin{array}{l}\text { Raj and Kokta 1991; Cui et al. 2008; Frone et al. 2011; Mokhene \& } \\
\text { Luyt 2014; Farsi 2012; Nishitani et al. 2016; Chen et al. 2017; Fang } \\
\text { et al. 2017; Gao et al. 2017, 2019; Zhou et al. 2017; Rashno et al. } \\
\text { 2018; Fathi et al. 2019, Ikladious et al. 2019; Liu et al. 2019 }\end{array}$ \\
\hline $\begin{array}{l}\text { Esterification (including } \\
\text { acetylation and } \\
\text { monomeric alkyl esters) }\end{array}$ & $\begin{array}{l}\text { Zhang et al. 2009; Taib et al. 2010; Ben Mbarek et al. 2013; Cavdar } \\
\text { et al. 2014; Cetin et al. 2015; Hung et al. 2016; Biswas et al. 2019; } \\
\text { John et al. 2019 }\end{array}$ \\
\hline $\begin{array}{l}\text { Maleic anhydride } \\
\text { polyethylene (MAPE)* }\end{array}$ & $\begin{array}{l}\text { Bouafif et al. 2010; Sewda \& Maiti 2010; Taib et al. 2010; } \\
\text { Zabihzadeh et al. 2010; Najafi \& Khademi-Eslam 2011; Yao et al. } \\
\text { 2011; Li 2012; Petchwattana et al. 2012; Ben Mbarek et al. 2013; } \\
\text { Gallagher \& McDonald 2013; Li et al. 2013; Hemmasi 2013; Liu et } \\
\text { al. 2013; Pollanen et al. 2013; Tisserat et al. 2013a,b; Schirp et al. } \\
\text { 2014; Tazi et al. 2014; Tong et al. 2014; Migneault et al. 2015; } \\
\text { Roumeli et al. 2015; Tisserat et al. 2015a,b; Boran et al. 2016; Tufan } \\
\text { \& Ayrilmis 2016; Cisneros-Lopez et al. 2017; Hosseini et al. 2017; } \\
\text { Zhou et al. 2017; Huang et al. 2018; Kajaks et al. 2018; } \\
\text { Lewandowska et al. 2018; Mu et al. 2018; Zhang et al. 2018; Biswas } \\
\text { et al. 2019; Ihamouchen et al. 2019; John et al. 2019 }\end{array}$ \\
\hline $\begin{array}{l}\text { Cui et al. 2008; Zhang et al. 2009; Kaymakci \& Ayrilmis 2014; Toupe } \\
\text { et al. 2014; Soccalingame et al. 2015; Chang et al. 2016; Elloumi } \text { et } \\
\text { al. 2016; Gomes et al. 2018; Igarashi et al. 2018; Durmus et al. } \\
\text { 2019; Simao et al. 2019; Xu et al. 2019 }\end{array}$ \\
\hline $\begin{array}{l}\text { Maleic anhydride } \\
\text { polypropylene (MAPP) }\end{array}$ \\
\hline
\end{tabular}

${ }^{*}$ Note: The typical way that polyethylene- or polypropylene grafted maleic anhydride (MAPE or MAPP) is employed is by mixing it with molten thermopolymer. Then, during the compounding operation, the cellulose-based surfaces are able to form esters by reaction with the anhydride groups of MAPE or MAPP.

\section{Concerns about Using Macroscopic Fibers}

While the above discussion provides reasons to suggest that "bigger is better," with respect to cellulose-based reinforcements for typical plastics, there are some contrary arguments to this assertion. Perhaps the most important of these is the fact that a relatively large reinforcement particle can act as a relatively large defect and point of crack initiation within a composite (Alavi et al. 2013). Such effects are especially to be anticipated when there is poor interfacial adhesion, e.g. when using unmodified wood fibers as a filler in a similarly unmodified polyolefin matrix.

There are cases in which larger cellulose-based fibrous elements may be inherently weaker than their smaller pieces. This can happen, for instance, in the case of compound fibers that are comprised of smaller elements. As discussed by Zimniewska et al. (2011), some bast fibers are bundles of elementary fibers held together by pectin and other compounds; such junctions can serve as weak points when the bundles are placed under stress. Such a mechanism might explain the results obtained by Nishitani et al. (2016). These researchers found that the positive effect of initial length of hemp fibers, with respect to the tensile properties of polyamide composites, did not increase much after the initial length was increased beyond $1 \mathrm{~mm}$. Presumably, beyond that point the junctions between elementary fibers may have become separated in response to the tensile forces applied to the composites. Similarly, Tarrés et al. (2019) reported a linear negative relationship between fiber length and intrinsic strength of henequen strands; again, this finding is consistent with the existence of weak points in compound fibers. Rong et al. (2001) go 
into more detail about how separations occurring between primary bast fibers in a multifiber strand (sisal bast fibers) provided a mechanism of preferential breakage after their formation into sisal-epoxy composites.

As shown by Di Guiseppe et al. (2017), the compounding of fibrous reinforcements within a polymer melt can generate large stresses. The accumulation of such stresses acting at the surface of cellulosic particles can be enough to cause them to fracture. This mechanism can explain many reports in which the average length of cellulosic fibers became greatly reduced in the course of extrusion to form a composite (Bouafif et al. 2010; Fonseca-Valero et al. 2015; Soccalingame et al. 2015). In such situations, potential advantages that one might have been expecting from larger particles will have been lost. It has been reported that larger cellulosic particles tend to experience more severe damage during extrusion to form a composite (Jaya et al. 2016).

Some other potential disadvantages of larger reinforcing elements in composites concern the quality or appearance of the surface. For instance, it has been reported that larger cellulose-based reinforcements (wood particles) yielded rougher surfaces of composites in comparison to when individual fibers were used as reinforcements (Wechsler and Hiziroglu 2007). Likewise, formation of agglomerates of reinforcing elements within composites can manifest itself as a rougher surface of the composite (Tisserat et al. 2013a).

\section{Expectations Based on Modeling}

It is inherently difficult to model the stresses and strains associated with a threedimensional composite filled with diverse particles aligning in multiple orientations. However, some insights have been provided by models that involve simplifications. Tucker and Liang (1999) considered the most relevant models, based on a set of simplifying assumptions. These included linear elastic behavior of both the plastic matrix and the reinforcing particles, isotropic behavior of the matrix, axisymmetric shape of the reinforcing particles, and perfect bonding at interfaces, with no slippage. None of the models considered by these authors showed any expected dependency of elastic modulus of the composite on the size of the reinforcement. Thus, none of the models considered can be used to predict any advantages of using nano-sized reinforcements, assuming that the shapes of different-sized particles are similar.

A possible objection to relying on the kinds of models considered by Tucker and Liang (1999) is that those models do not consider potential effects at the nano-scale. An argument could be made, for instance, that the very high surface areas associated with nanocellulose could give rise to effects that would not be otherwise predicted. For example, there might be contributions from forces acting between particles within a medium. Thus, the previously mentioned expectation of a "nano-advantage" (Fu et al. 2008; Tanpichai and Wootthikanokkhan 2018) ultimately deserves to be evaluated on an experimental basis, as in the following section.

\section{EXPERIMENTAL FINDINGS}

\section{Strategy: Consider Big Picture First, Then Details}

Since there is a very large amount of scientific literature related to plastic composites reinforced by cellulose-based materials, it was necessary to make some strategic decisions on how to organize this review of the literature. It was decided to divide the discussion of experimental findings into two parts. The first part attempts to answer 
some broad questions, based on selection of a common matrix polymer. The idea is that by focusing on a large number of studies all evaluating the same kind of polymer, it can be possible to look for characteristic differences in the nature of results that can be obtained with addition of very different sizes of cellulose-based reinforcements. The second step was to focus on specific publications where the researchers happened to study effects of particles having different sizes under their own fixed conditions of matrix type and processing conditions.

Why hybrid composite studies were not included in the data set

There is much current interest in the concept of hybrid composites, i.e. composites in which two or more kinds of reinforcement are used simultaneously within a matrix. However, such combinations were not included in the publications considered for the present analysis. The primary reason was to avoid additional complexity. As will be shown, it is already a difficult challenge to find clear evidence for dependencies of composite properties on the dimensions of reinforcing particles, and properties of hybrid composites are yet harder to account for. An earlier review of hybrid composites (Hubbe 2017) found only a few examples of studies giving clear support for the idea that a combination of two different types of reinforcement (including different sizes or shapes) can be beneficial for composite strength. Most results of work involving such hybrid composites either can be understood by "rule of mixtures" estimates or are merely inconclusive with respect to the theory of hybrid composites (Philips 1976).

\section{Coupling agents and surface modification regarded as a second focus}

Although coupling agents and surface modifications and treatments were not the main issues considered during the formulation of the present study, the review of the literature immediately made it apparent that, just like the "elephant in the room," issues related to surface adhesion can play major and even dominant roles in many situations of interest (George et al. 2001; Belcacem and Gandini 2005; Verma and Jain 2017). Accordingly, in many of the tables and figures provided below, table entries and data points will be presented with an indication of whether or not there was some form of compatibilization employed. It must be borne in mind, however, that the range of reported studies is extremely diverse. Hence, even if a given study indicates that "yes," there was a coupling agent or surface modification, one must be open to the possibility that the treatment might have been extremely ineffective or have had negative effects in a specific piece of published research.

\section{Largest dimension used as the key measure}

A third key choice that was made to simplify the analysis that follows was to consider the largest dimension of the reinforcing particle as the only measure of particle size. This was done because much of the reported data is based on use of sieving through standard mesh screens as a way to obtain particles within specified size ranges. Only in a minority of cases do such publications provide sufficient information to estimate aspect ratios and fiber widths. Fuller comprehensive analysis of such issues is left as an opportunity for future investigations. 


\section{Part A: Studies Dealing with a Selected Common Polymer Matrix}

Selection of a common plastic matrix material for data mining

The analyses and comparisons discussed in this section are based on an arbitrary selection of a single kind of polymer matrix. By focusing on a large number of studies all dealing with only one class of plastic, the goal was to try to address some broad questions, such as the following:

- When comparing results over a very broad range of reinforcement sizes, is there an observable effect of particle size on the strength attributes of composites?

- In addition to any effects attributable to particle size, is there an observable influence of coupling agents or surface modification of the cellulose-based reinforcement particles?

High-density polypropylene (HDPE) was selected as the polymer matrix for this part of the study. The choice of HDPE as a focus area is justified not only by its very widespread use as an unmodified polymer material, but also because of the large number of studies that have been conducted involving cellulose-based reinforcements. HDPE also presents a specific challenge that is of great interest to researchers: The low surface energy of HDPE surfaces tend to bond poorly to unmodified cellulosic surfaces (Hou et al. 2017; Sakakibara et al. 2017; Zhang et al. 2018; Gao et al. 2019), so that a majority of related published research includes evaluating effects of compatibilizing treatments. Another characteristic of interest is HDPE's moderately flexible nature. Tensile modulus values of HDPE have been reported most often in the range 0.2 to $2 \mathrm{GPa}$ (see Table A in the Appendix), which is much lower than the values reported for crystalline cellulose (CNC), which has been reported as $138 \mathrm{GPa}$ (Sakurada et al. 1962). This contrast implies that the combination of HDPE and cellulose-based reinforcements at least has the potential to achieve elastic modulus values that are significantly higher than that of the matrix polymer by itself.

The goal of this analysis is to determine whether, above the variations associated with other factors such as particle shape and orientation, it is still possible to detect statistically significant trends in the data. Four approaches were employed in the Part A in an attempt to deal with inherent variations in the details of different studies. First, all the data considered here deals with the same nominal matrix material, HDPE. Second, since a very large number of studies have been focused on HDPE, the number of individual results to be compared likewise is about as high as can be found in the literature at this point. Third, to minimize the impact of differences in the matrix properties in the compared studies, the data were compared in the form of ratios of observed data relative to the unfilled corresponding matrix value reported in a given study. Fourth, the range of particle size considered in this work was very large.

Before considering experimental data, it is important to note that large differences can be expected in the matrix polymer, even when the designation "HDPE" was used in each of the systems considered. Factors such as molecular mass distributions, degrees of crystallinity, and purity can be expected to show differences. Processing conditions also can be widely different among nominally similar experimental studies. For example, the rate of cooling a composite after compounding, which can be different from study to study, can be expected to affect the crystallinity and related properties of the polymer (Supaphol and Spruiell 2002; Kundu et al. 2003). The methods of processing and formation of the composites were grouped together, rather than being isolated. As a way to minimize the 
influence of differences in matrix properties, the data to be considered in this part are shown mainly on a relative basis, comparing the composite properties to those of the corresponding specimen of unfilled HDPE in each of the studies.

\section{Tensile strength}

Combined data obtained from approximately 50 separate published studies are presented in Fig. 2, all based on experiments in which cellulose-based elements were used to reinforce HDPE matrices.

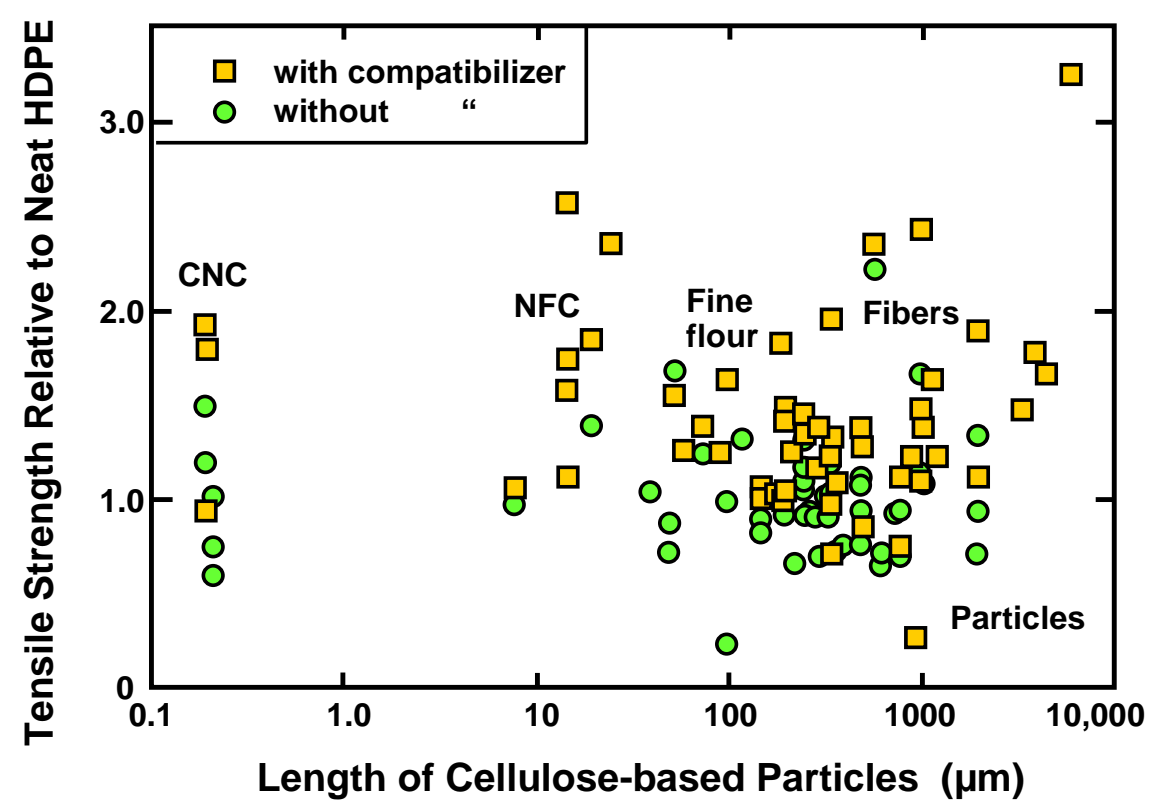

Fig. 2. Published results for the relative change in tensile breaking strength, compared to that of the HDPE matrix employed in each study, vs. the length (usually determined by screening) of a cellulose-based reinforcement. Circle symbols correspond to untreated cellulosic particles. Squares correspond to use of a coupling agent or surface agent intended (by the given authors) to improve the adhesion.

The vertical axis represents the ratio of the observed tensile breaking stress to that of the neat, unfilled HDPE by itself in each respective study. The horizontal axis corresponds to the reported size or length (often based on the reported mesh size) of the particles. Note that the scale of the horizontal axis is logarithmic, showing a range of about five factors of ten. Experimental details are listed in Table A, which appears in the Appendix. The contents of reinforcements, by mass, were generally in the range of 20 to $60 \%$ for most reported results. However, lower amounts, usually in the range of 1 to $10 \%$, were most commonly used for systems reinforced by nanocellulose (CNC and NFC).

Two main conclusions can be drawn from the plotted results in Fig. 2. First, there was no discernable trend for tensile breaking stress as a function of the logarithm of particle size. Rather, there was a very large range in relative tensile strengths observed within each size range within the plotted data. A linear regression of all the data (110 observations) yielded an $\mathrm{R}^{2}$ value of 0.00012 and a slope of having a $95 \%$ confidence interval of -0.38 to +0.43 . Thus, there was no statistically significant relationship. 
The second main conclusion is that those systems employing a compatibilizer (i.e. either a coupling agent or specific treatment of the cellulosic surface with the goal of making it more compatible with the HDPE) generally yielded higher strength. On a quantitative basis, the average value of relative tensile strength for all of the data was 1.21 , while it was 1.40 when considering just the compatibilized systems.

A further linear regression calculation was carried out considering just the 59 observations associated with compatibilized systems. In this case the $\mathrm{R}^{2}$ value for the linear relationship between tensile strength and size was 0.00180 and the slope of the regression line had a $95 \%$ confidence interval between -0.58 and 0.42 . Thus, for the compatibilized system, there still was no statistically significant relationship between tensile breaking strength and the logarithm of particle size in HDPE composites.

\section{Tensile modulus}

Results for the relative tensile modulus (normalized to the modulus of the neat HDPE in each study) vs. the logarithm of particle size are shown in Fig. 3.

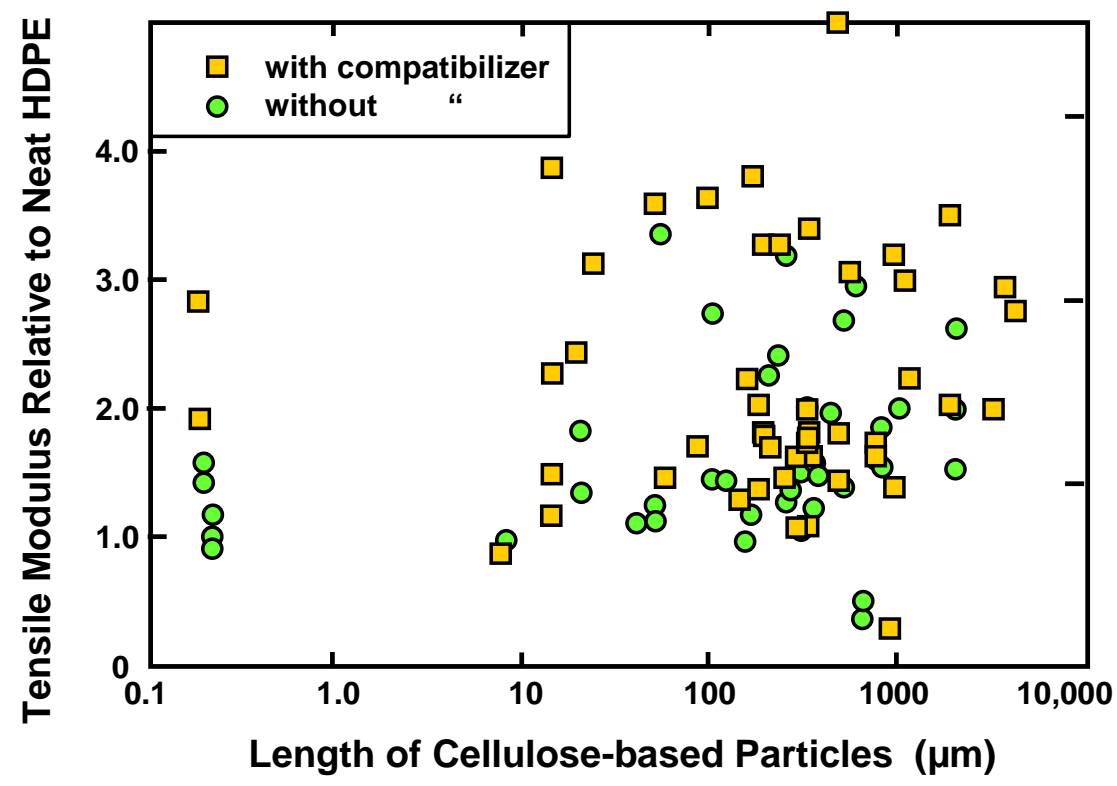

Fig. 3. Published results for the relative change in tensile modulus, compared to that of the HDPE matrix employed in each study, vs. the length (usually determined by screening) of a cellulose-based reinforcement

As above, there was a large range of tensile modulus values at each size range. A linear regression of all the data (98 observations) gave an $\mathrm{R}^{2}$ value of 0.047 and a slope having a $95 \%$ confidence interval of +0.0130 to +0.267 . Given that this whole range is (sometimes just barely) positive in value, this result implies a significant increase in relative tensile modulus with increasing particle size. However, the weakness of this statistical fit must be emphasized. When considering only the compatibilized systems, the $\mathrm{R}^{2}$ value was 0.0099 and the slope did not show a statistically significant trend with respect to particle size.

Regarding the effects of the compatibilizing treatments, untreated reinforcements yielded an average increase in tensile modulus of 2.17 relative to the neat HDPE, whereas 
the systems with coupling agents or surface treatments yielded an average relative increase of 2.41 .

\section{Tensile elongation}

Results for tensile elongation at breakage, relative to the elongation of the respective HDPE samples alone, are shown in Fig 4. Three things are worth noting about these results. Firstly, there were many data points very close to zero at the bottom of the plot, which is reflective of the inclusion of particles inducing very brittle systems. Secondly, there were a few systems, representing very different particle sizes, in which the elongation at break was about as long, and in a couple cases even much longer than the matrix plastic by itself. Thirdly, there was no reliably discernable difference in results obtained with very small cellulosic particles in comparison to using very large ones. Although the most common observation was for reinforcement to greatly decrease the elongation to break when compared to the corresponding neat HDPE, there was a lot of variation evident among different studies.

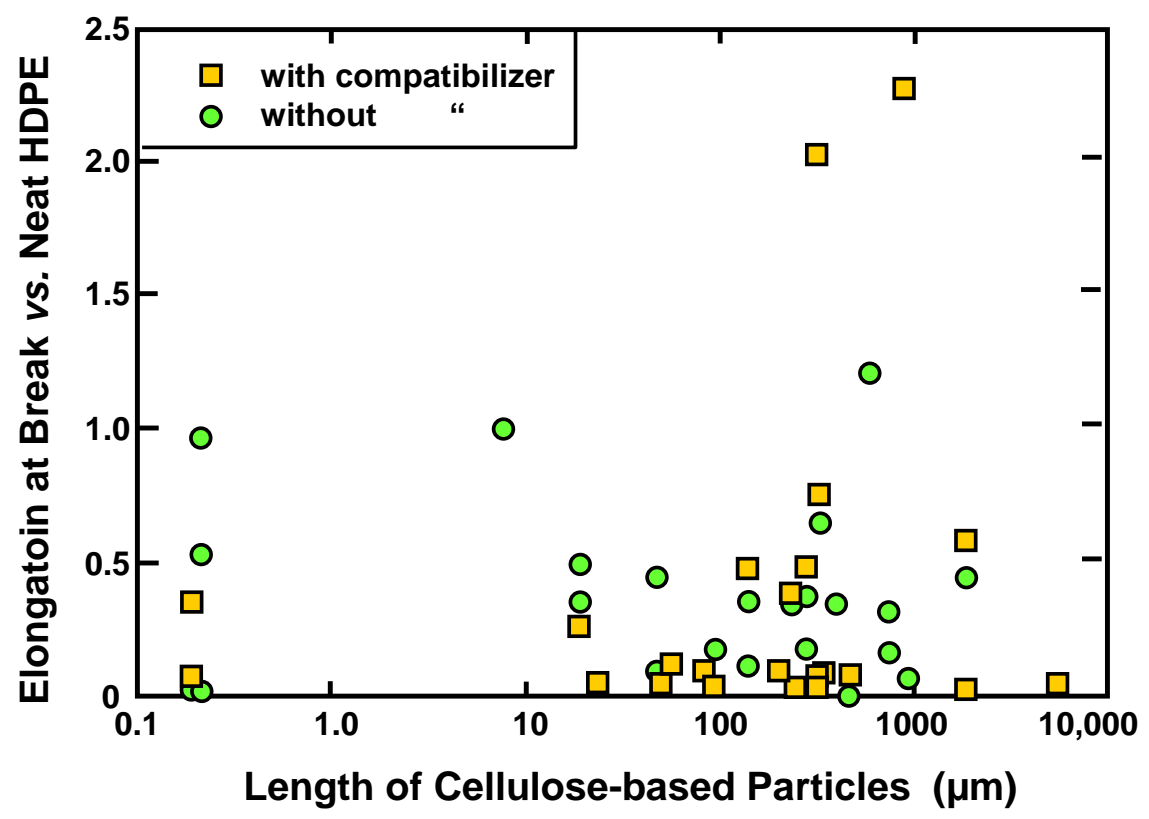

Fig. 4. Published results for the change in tensile modulus, relative to that of the HDPE matrix employed in each study, vs. the length (usually determined by screening) of a cellulose-based reinforcement

\section{Flexural strength}

Figure 5 shows data for flexural strength, i.e. the amount of bending force needed to cause breakage of the HDPE composites. Notably, for this analysis there were no data corresponding to the smallest of the particles, the cellulose nanocrystals (CNC). Although the range of particle size was more limited than in the case of tensile strength testing considered above, the data from the studies reveal a trend toward increasing flexural strength with increasing size of the reinforcement, especially when considering systems with compatibilizing treatments (plotted square symbols). When considering all the data, the $\mathrm{R}^{2}$ value was 0.203 and the $95 \%$ confidence interval for the slope of the linear 
regression line was from 0.226 to 0.820 , indicating a statistically significant increase in flexural strength with increasing particle size. When considering just the systems with compatibilization ( 24 data points), the $\mathrm{R}^{2}$ value was 0.397 and the $95 \%$ confidence range for the slope was 0.317 to 1.078 , again indicating a statistically significant trend of increasing flexural strength with increasing particle size.

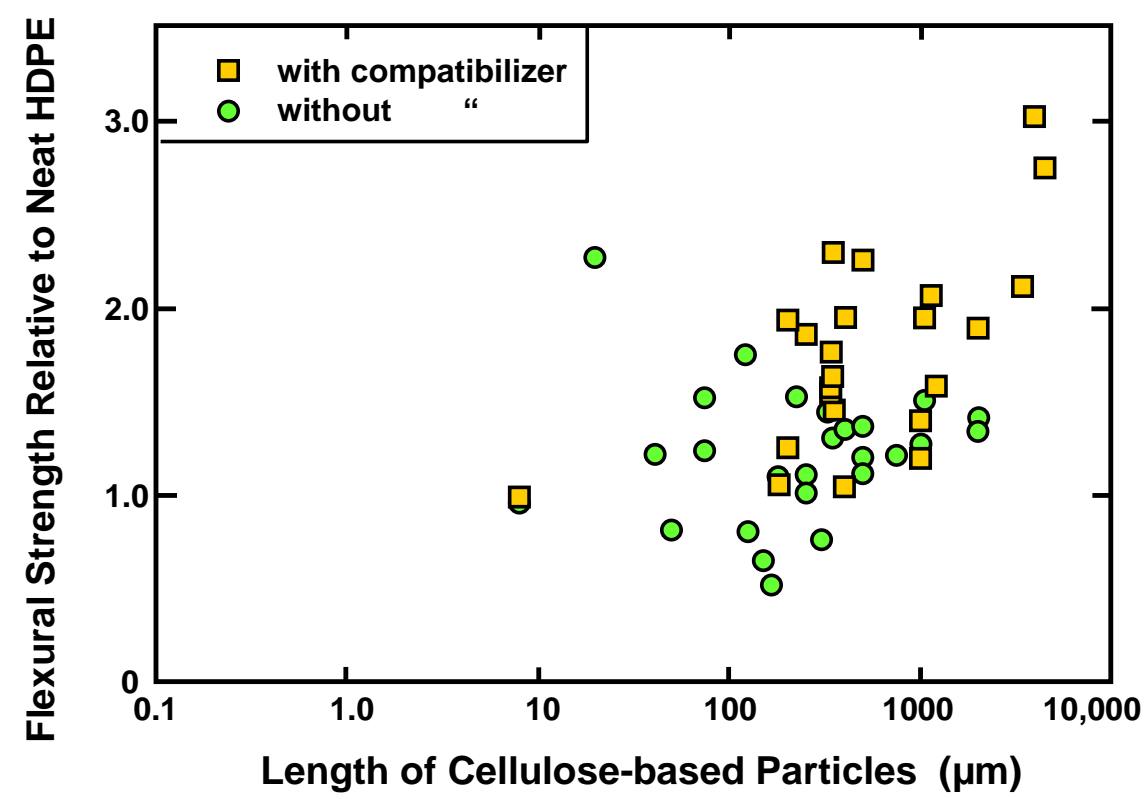

Fig. 5. Published results for the change in flexural strength, relative to that of the HDPE matrix employed in each study, vs. the length (usually determined by screening) of a cellulose-based reinforcement

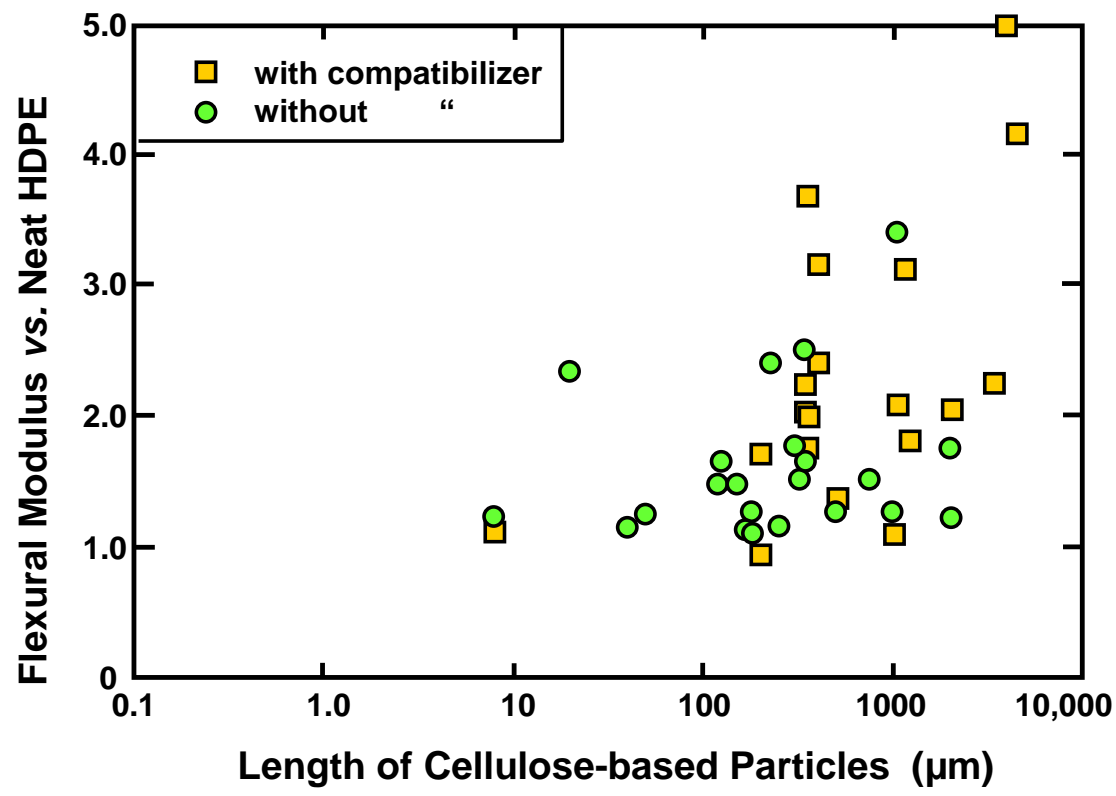

Fig. 6. Published results for the change in flexural modulus, relative to that of the HDPE matrix employed in each study, vs. the length (usually determined by screening) of a cellulose-based reinforcement 


\section{Flexural modulus}

As shown in Fig. 6, a positive trend vs. the logarithm of particle size also was apparent in the plotted results for flexural modulus. When considering all the data together, the $\mathrm{R}^{2}$ value was 0.216 and the $95 \%$ confidence range for the slope was 0.130 to 0.519 , indicating a significant positive trend of flexural modulus vs. particle size. When considering only the systems with compatibilization, the $\mathrm{R}^{2}$ value was 0.294 and the $95 \%$ confidence range for the slope was 0.080 to 0.544 , again indicating a significant positive trend in flexural modulus $v s$. the logarithm of particle size of the reinforcements.

\section{Studies of HDPE in which particle size was an independent parameter}

While most of the published studies involving HDPE composites with cellulosebased reinforcements were focused on other composite preparation issues, some studies compared results for particles having different size under matched processing conditions. Because some of these articles did not include evaluation of the strength of the neat HDPE by itself, the data are plotted as actual rather than relative values. Figure 7 shows the data for tensile breaking stress $(\mathrm{MPa})$. Note that the lines shown in the figure connect data points corresponding to the same published article, but with differing sizes of reinforcing particles.

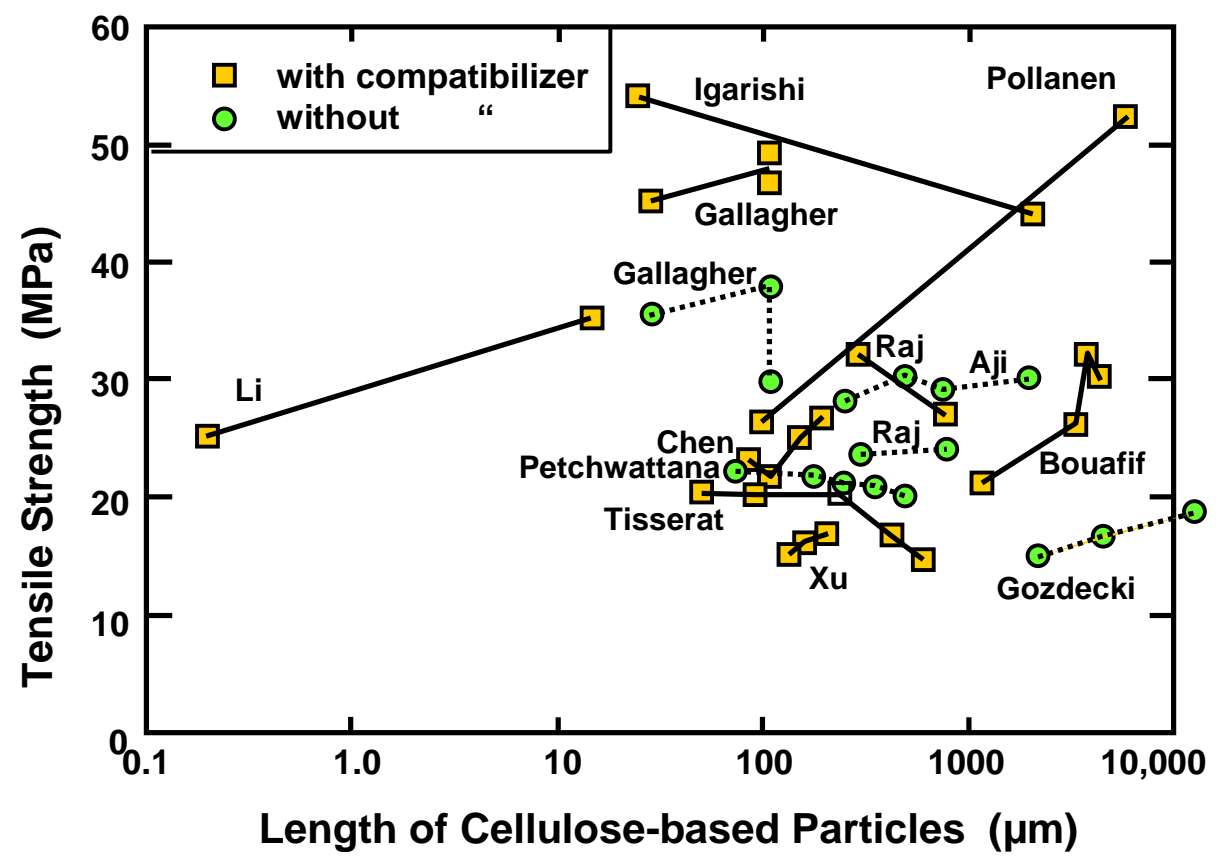

Fig. 7. Published results for tensile breaking strength of HDPE composites for studies that considered more than one particle size under the same conditions of composite preparation. Articles represented in the figure are as follows: (Raj and Kokta 1991; Bouafif et al. 2010; Aji et al. 2011; Petchwattana et al. 2012; Gallagher and McDonald 2013; Pollanen et al. 2013; Li et al. 2014; Ogah and Afiukwa 2014; Gozdecki and Wilczynski 2015; Tisserat et al. 2015; Xu et al. 2016; Chen et al. 2018; Igarishi et al. 2018).

Two main findings can be concluded from a general inspection of the results presented in Fig. 7. First, any effects that might be attributed to particle size, within given studies, were generally small to moderate in terms of the relative difference in tensile strength. Second, while there were a few studies that showed instances of decreasing 
composite strength with increasing particle size, most of the studies showed the contrary. Thus, the results support the idea that larger particle size is usually associated with moderately higher tensile breaking stress.

A decrease in tensile strength with increasing particle size is shown by the data of Igarishi et al. (2018). These researchers compared nanofibrillated cellulose versus bleached softwood kraft fibers. The higher strength achieved with the NFC possibly might be explained by an expected higher aspect ratio, leading to an enhanced reinforcing ability.

Raj and Kokta (1991) observed decreased composite strength with increasing size of reinforcements obtained from the same aspen wood chips. Chemithermomechanical pulp (CTMP) was made using a pressurized refining process, which is a commonly used process in the pulp and paper industry. Wood flour was obtained by grinding the same chips in a mill. The authors did not offer any explanation for the somewhat different performance of the two types of reinforcement.

Tisserat et al. (2015a) explained their observed trend of decreasing tensile strength with increasing particle size by reference to particle shape. They observed that during the milling of paulownia wood, the smaller particles tended to have a higher aspect ratio, enhancing their reinforcing capability. Note, however, that the three smallest plotted categories from that study gave approximately the same strength, representing 1.24 to 1.30 times the tensile strength of the neat HDPE.

Figure 8 shows a plot for the tensile modulus, from studies evaluating reinforcing particles of different sizes under the same conditions of HDPE composite preparation. Here the general trend of almost every study was an increased tensile modulus with increasing size of the cellulose-based reinforcement particles.

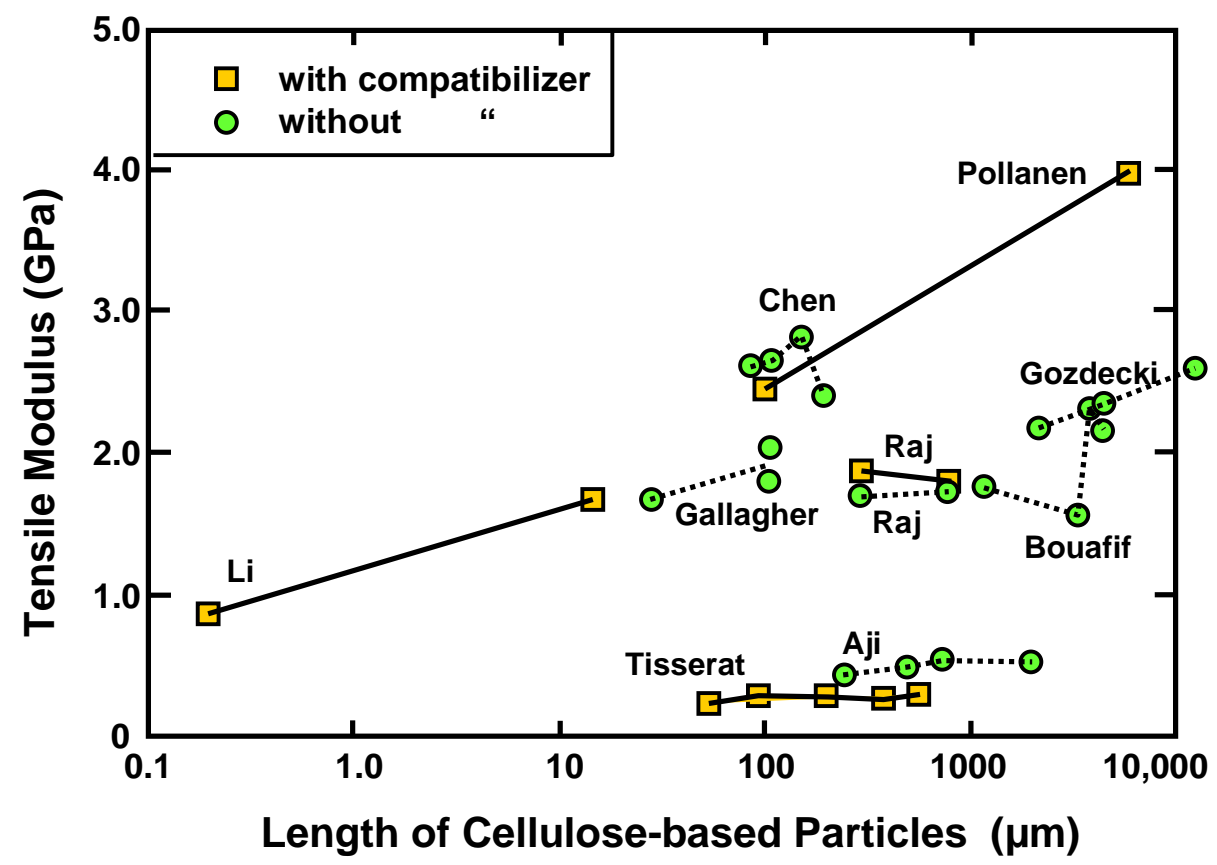

Fig. 8. Published results for tensile modulus of HDPE composites for studies that considered more than one particle size under the same conditions of composite preparation. Articles represented in the figure are as follows: (Aji et al. 2011; Bouafif et al. 2010; Chen et al. 2018; Gallagher and McDonald 2013; Gozdecki and Wilczynski 2015; Li et al. 2014; Pollanen et al. 2013; Raj and Kokta 1991; Tisserat et al. 2015). 
It is apparent that the magnitudes of tensile modulus achieved showed large differences from study to study. It should be borne in mind that the attributes of the base HDPE can be expected to vary from study to study, including the molecular mass, polymer dispersity, crystallinity, and even the purity. Some of the studies employed recycled HDPE, but notably the two studies reporting the lowest tensile modulus results (Aji et al. 2011; Tisserat et al. 2015b) did not indicate usage of recycled HDPE.

\section{General findings for $H D P E$}

Based on results from the studies dealing with HDPE as a matrix (Figs. 2 to 8), some general summaries can be drawn:

- Measures to improve the compatibility between the HDPE and the cellulose-based reinforcement tend to have a major effect, which is typically more important than other factors such as particle size. To achieve this, some of the most-reported systems for compatibilization include surface modification of the cellulosic material with trimethoxy silane derivatives (Ben Mbarek et al. 2013; Chen et al. 2017; Fang et al. 2017; Zhou et al. 2017; Gao et al. 2019) or esterification (Zhang et al. 2009; Taib et al. 2010; Cetin et al. 2015). The most popular coupling agents that are typically added to the matrix material before compounding or compression molding (hot-press) are maleic anhydride polyethylene (MAPE) (Taib et al. 2010; Li et al. 2012; Gallagher and McDonald 2013; Liu et al. 2013; Tisserat et al. 2013; Migneault et al. 2015; Roumeli et al. 2015; Chang et al. 2016; Cisneros-Lopez et al. 2017; Huang et al. 2018; Zhang et al. 2018; Ihamounchen et al. 2019) and maleic anhydride polypropylene (MAPP) (Cui et al. 2008; John et al. 2010; Elloumi et al. 2016).

- For tensile breaking strength, considering many studies for which the range of particle sizes spanned five orders of magnitude, there was generally only a weak positive relationship, if any, between mechanical strength and particle size of the reinforcements. This relationship was not statistically significant when considering all the data together. However, the relationship was demonstrated in several studies where particles of different sizes were compared in HDPE under matched conditions (Bouafif et al. 2010; Petchwattana et al. 2012; Gallagher and McDonald 2013; Pollanen et al. 2013; Li et al. 2014; Gozdecki and Wilcynski 2015; Xu et al. 2016).

- For tensile modulus and flexural modulus, there was a statistically significant increase in modulus with increasing size of the reinforcing particles, especially in the case of systems with some form of compatibilization, meaning a surface treatment or use of a coupling agent added to the matrix material before compounding. This finding is tentatively attributed to the fact that tests of flexural modulus are likely to involve stress levels below what will cause interfacial separation. Because of this, the greater stiffness of cellulosic particles, relative to typical HDPE, are able to make a significant contribution to composite stiffness.

- Evaluation of test data for elongation to failure gave diverse results, but the majority of the findings showed greatly reduced elongation in the presence of reinforcing particles, whether these were large or very small. These findings are consistent with separation occurring at interfaces, leading to brittle failure and the propagation of cracks at weak points. 
The numerical results of statistical analysis, as reported in this section, showed several cases in which either there was a lack of any significant relationship or where higher particle size gave a statistically significant advantage in terms of strength. There are reasons to be cautious regarding those cases that appeared to show statistically significance. First, it can be argued that the data included in such analysis does not truly meet the requirement of independence. Rather, data obtained from different studies can be regarded as showing systematic rather than random differences. Second, it can be argued that the combined data set obtained from different studies would not necessarily involve a normal distribution of values.

When considered as a whole, the take-away message from Part A can be stated as follows: For the first time, the relative properties have been compared for a very large number of composites prepared with cellulose-based reinforcing particles having very different sizes, all in the same nominal matrix material (HDPE). Statistical analysis of the relationships between properties and particle size showed cases of either no significant relationship or a weak but significant positive relationship. In no case did the regression analysis support any inherent advantage of small particles when the goal is to achieve higher composite strength properties.

\section{Part B: Studies Comparing Differently Sized Reinforcements}

Having considered a broad range of data, in the case of HDPE, the rest of this review will focus on studies in which particles of different size were compared under matched conditions as reinforcements in matrix polymers other than HDPE. Due to differences in properties such as elastic modulus, surface energy, and hydrogen bonding ability, it should not be necessarily assumed that effects of cellulosic reinforcement particles would follow the same trends as have been discussed for HPDE. An emphasis here will be on studies in which the researchers tested cellulose-based particles of different size in a common matrix material.

\section{Polypropylene}

Studies in which polypropylene served as the matrix, and cellulose particles of different size were considered as reinforcements are listed in Table 4:

Table 4. Studies Considering Effects of Particle Size of Cellulose-based Reinforcement in Polypropylene

\begin{tabular}{|l|l|}
\hline System Considered & Reference \\
\hline Pine particles of 10 mesh and 50 mesh compared & Wechsler and Hiziroglu 2007 \\
\hline Oak and pine wood fibers; effects of extraction & Ashori \& Nourbakhsh 2010 \\
\hline Nut shells and argan particles & Essabir et al. 2013 \\
\hline Wood: four length distributions, three damage levels & Thumm \& Dickson 2013 \\
\hline Breakdown of cellulose particles during compounding & Soccalingame et al. 2015 \\
\hline Wood fibers; emphasis on rheological behavior & Durmus et al. 2019 \\
\hline Nanofibers and nanocrystals were compared & Neves et al. 2019 \\
\hline Henequen strands; optimization of coupling agent dose & Tarrés et al. 2019 \\
\hline
\end{tabular}

Ashori et al. (2010) observed generally higher breaking stress and modulus values (both tensile and flexural) for polypropylene wood fiber composites reinforced with pine fibers, compared to oak fibers, which are smaller. In contrast, Durmus et al. (2019) did not 
observe a consistent trend with increasing size classification of the wood fibers; rather, they obtained higher tensile strength and modulus for both larger (350 to $425 \mu \mathrm{m}$ ) and smaller $(<250 \mu \mathrm{m})$ reinforcements in comparison to intermediate size $(250$ to $350 \mu \mathrm{m})$. Thumm and Dickson (2013) found that the length of wood fiber used for reinforcement of polypropylene did not have a large effect unless it fell below a critical value of about 0.8 $\mathrm{mm}$. By contrast, fiber distributions having a mean length of about $1.3 \mathrm{~mm}$ achieved equally good flexural strength and modulus as longer fibers (e.g. $2 \mathrm{~mm}$ and $3 \mathrm{~mm}$ average fiber length). When comparing nanofibrillated cellulose (NFC) with cellulose nanocrystals (CNC), Neves et al. (2019) found substantial increases in compressive strength of the resulting polypropylene composite foams only in the case of the NFC particles, which were larger. Wechsler and Hiziroglu (2007) observed no significant difference in modulus of elasticity when comparing polypropylene composites prepared with pine particles of different size.

Essabir et al. (2013) reported an increase in elastic modulus with a decrease in average particle size. All of their composites showed lower tensile breaking strength in comparison with the neat polypropylene. These results are consistent with poor adhesion between the matrix and reinforcement. Since relatively large reinforcing particles, when poorly adhering, can be expected to provide large defects in the structure, such a mechanism is consistent with the size dependency of the mechanical strength results.

\section{Polyamides}

Polyamides, in the family of nylons, are well known as strong thermoplastic polymers. Because they have a more polar nature than the HDPE and polypropylene just considered, they can be expected to have better interfacial adhesion to unmodified cellulosic articles. However, the higher temperature processing requirements of polyamides can restrict the use of wood-based materials. Relatively pure cellulose fibers or particles, which have a relatively high thermal tolerance (Yang et al. 2007), may be required.

Peng et al. (2015) carried out an especially interesting study in which polyamide resin was compounded with three contrasting sizes of cellulose particles: cellulose nanocrystals (CMC), nanofibrillated cellulose (NFC), and microcrystalline cellulose (MCC). Due to air-drying of these particle forms, some inherent clustering of the particles was expected. Detectable gains in tensile modulus were observed with all three types of reinforcement, but the most favorable choice of reinforcement was dependent on the level of loading. At a loading level of $2.5 \%$, the $\mathrm{CNC}$ gave the largest increase in tensile modulus (a factor of about 1.08 relative to the neat polyamide). At an intermediate addition level of $5 \%$ the NFC gave the biggest reinforcing effect (factor $=1.19$ ), and at the highest addition level of $10 \%$ the MCC gave the overall greatest increase in tensile modulus (factor $=1.30$ ). Since the larger MCC particles have lower surface area per unit mass, such results suggest that there may be an optimum amount of surface area of reinforcement in the studied system.

Considering much larger particle sizes, Nishitani et al. (2016) filled polyamide matrices with hemp fibers that had been previously cut to lengths of 5, 10, 20, and $50 \mathrm{~mm}$. The material was surface modified using a two-fold treatment with alkaline extraction and silanization treatment to improve interfacial adhesion. Following extrusion, the tensile strength and modulus results both increased with an increase of initial particle size from 5 to $10 \mathrm{~mm}$. Further increases in length yielded lesser benefits, which suggested to the 
researchers that the longer fibers were at least partly shortened during the process of extrusion.

\section{Poly-(lactic acid) (PLA)}

Probably because PLA is a thermoplastic polymer that can be readily obtained by processing of chemicals derived from plant sources, there has been intense interest in exploring its potential uses and modifications. PLA is a polyester, and it can be either extruded or cast from solvent. Due to the weak, relatively brittle nature of neat PLA, it is widely recognized that it needs to be modified, for instance by use of plasticizers and reinforcing particles (Farah et al. 2016). Selected articles in which cellulose-based particles were used to reinforce PLA composites are listed in Table 5.

Table 5. Studies in Which Cellulosic Particles Were Used as Reinforcement in PLA Composites

\begin{tabular}{|l|l|}
\hline System Considered & Reference \\
\hline CNC compared with MFC fibers; silane treatment & Frone et al. 2011 \\
\hline NFC compared with ordinary wood-pulp fibers & Kowalczyk et al. 2011 \\
\hline Ball-milled celluloses; extrusion; fractal analysis & Gao \& Qiang 2017 \\
\hline Bamboo fiber of different lengths & Jiang et al. 2018 \\
\hline Ball-milling for different times; effects of mean size & Qiang et al. 2018 \\
\hline Regenerated cellulose microfibrils compared with NFC & Tanpichai \& W. 2018 \\
\hline Cotton fibers with starch as compatibilizer & de Macedo et al. 2019 \\
\hline NFC used with extrusion and injection molding & Peric et al. 2019 \\
\hline CNC, with attention to problems of poor distribution & Wang et al. 2019b \\
\hline
\end{tabular}

Several of the listed studies involved direct comparison of different sizes of cellulose reinforcement particles under matched conditions of PLA composite preparation. As shown in Fig. 9, Frone et al. showed that neither MCC nor MFC, either with or without silane treatment of the cellulosic surfaces, was able to increase the elastic modulus relative to the neat PLA polymer.

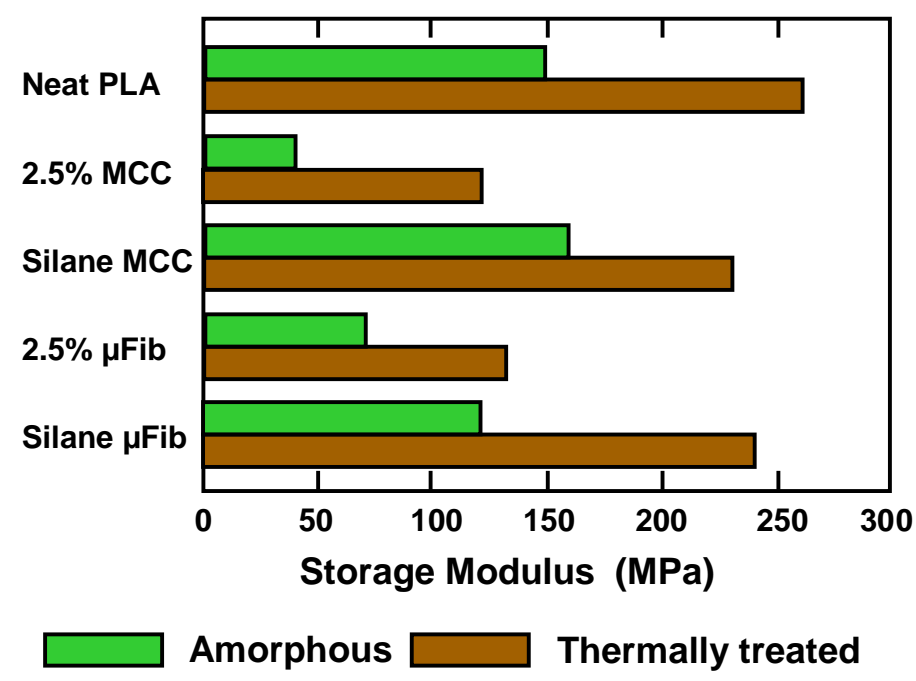

Fig. 9. Effects microcrystalline cellulose (MCC) and microfibers on the storage modulus of PLA (data of Frone et al. 2011, plotted for the first time) 
The silane treatment was shown to be very important, making it possible (especially in the case of the MCC), to essentially match the modulus obtained with neat PLA. In contrast, a thermal annealing treatment yielded substantial increases in modulus in all cases, with the best overall results for the unfilled PLA.

Jiang et al. (2018) compared the effects of bamboo-derived fibers of different length classes ( $<1 \mathrm{~mm}$; 4 to $5 \mathrm{~mm} ; 9$ to $10 \mathrm{~mm}$ ). Tensile and flexural strength and modulus were all increased with the addition of reinforcing fibers of any of the size ranges. The highest mechanical properties were generally achieved with the intermediate size of particles. However, the highest tensile strength was obtained with the longest bamboo fibers. Microscopic evidence indicated good adhesion between the fibers and the PLA matrix in all cases. The authors attributed the poorer performance of the longest fibers, in most cases, to more extensive fiber entanglement, which was confirmed by microscopic images.

Kowalczyk et al. (2011) compared the effects of regenerated cellulose fibers of two highly contrasting sizes. SEM micrographs showed that a class called "CSFs" had diameters of 10 to $70 \mu \mathrm{m}$, whereas fibers called "CNFs" had diameters of 200 to $300 \mathrm{~nm}$. Based on mechanical tests at room temperature, the smaller (CNF) particles gave higher tensile and flexural strength at a $2 \%$ level of loading. However, the highest tensile strength was found at a $20 \%$ loading when using the larger (CSF) reinforcement.

In their study of ball-milled bleached softwood kraft pulp, Qiang et al. (2018) found mixed results for the effects of particle size in PLA composites. In the case of tensile strength, the reinforced PLA always gave lower stress to breakage in comparison to the neat PLA. However, the most favorable results, for maintaining tensile strength, were at the highest duration of ball milling, consistent with the smallest reinforcing particles. For tensile modulus, the presence of reinforcements generally yielded higher values, especially at the highest level $(20 \mathrm{wt} \%)$ of loading. The cellulose that had been ball-milled for the least time yielded the greatest increase in modulus. Overall, the results are consistent with the idea that the evaluation of modulus generally does not involve stresses large enough to cause interfacial separation, thereby allowing the longest fibers to more fully express their stiffening effect. By contrast, the longer fibers would be expected to provide large areas of weakness and likely points of crack initiation during tensile strength testing.

In another study comparing effects of regenerated cellulose fibers with nanofibrillated fibers prepared therefrom, Tanpichai and Wootthikanokkhan (2018) reported higher tensile breaking strength and modulus in the case of the smaller particles, the NFC. The authors attributed the better results, at least in part, to a better interaction of the NFC with the matrix.

\section{Other Polyesters}

Rahman et al. (2018) studied flat-pressed composites of recycled polyester (PET) with wood particles of different size. Relatively large wood particles at a loading level of $50 \%$ gave the highest values of modulus of elasticity. The composite product also had lower density than the base polymer. Though the cited authors did not employ a coupling agent in their work, the results suggest that a coupling agent could have enabled higher strength properties.

Butron et al. (2019) recently used a solvent-casting method to prepare films based on a bio-based polyester with cellulose nanocrystals. The solvent casting method permits high levels of reinforcement without damaging the cellulosic material or reducing the particle length. The elastic modulus of the resulting films increased almost linearly with 
CNC content up to $50 \%$, the highest loading considered. However, the composites with such high amounts of CNC were described as very brittle; the maximum stress was about half that of the base polymer. At a $20 \%$ loading of CNC the stress to breakage was equal to that of the neat polyester. The highest stresses and strains to breakage were obtained with loadings in the range 2 to $5 \%$ by weight, which is a common level when compounding with CNC.

\section{Polyurethanes}

Tian et al. (2019) noted that hydrogen bonding can be expected to play an important role in the interaction between cellulose and polyurethane. They used this concept in explaining their promising results with cellulose nanocrystals as a filler for polyurethane. Substantial increases in both tensile modulus and strength to breakage were observed.

Chen et al. (2019) prepared composites from waterborne polyurethane filled with nanofibrillated cellulose at a loading of $3 \%$ for use in 3D printing. The NFC particles could be added either during polymer synthesis or to the emulsion after its preparation. The casting method of preparation allowed film preparation with little chance of damage to the reinforcing particles. Large increases in elastic modulus were achieved, while maintaining the stress to breakage in systems prepared with an excess amount of trimethylamine (TEA), which was found to increase the viscosity of the resulting formulations.

None of the reports involving polyurethane composites compared cellulose-based particles of differing size. However, cited work (Chen et al. 2019, Tian et al. 2019) suggests that this would be a good candidate for studies with different sizes of cellulose reinforcement. That is because certain polyester resins can be cured with low to moderate temperature, avoiding damage to cellulosic reinforcements.

\section{Poly-(ethylene oxide) and related}

$\mathrm{Xu}$ et al. (2013) compared polyethylene oxide composites filled with either cellulose nanocrystals or nanofibrils. The larger NFC particles conferred higher strength and modulus to cast films, which was attributed to their higher aspect ratio. Sapkota et al. (2017) similarly compared two different CNC types having different aspect ratio; their matrix polymer was ethylene oxide-epichlorohydrin. The results were strongly affected by the presence of some particles having higher aspect ratio. Favorable results, in terms of composite stiffness, were achieved with 50 to $75 \%$ of the longer CNCs.

\section{Acrylics}

As listed in Table 6, several research groups have obtained promising results for various acrylic polymers filled with nanocellulose particles. These systems offer greater flexibility for composite preparation.

Table 6. Studies of Acrylic Polymers Filled with Nanocellulose

\begin{tabular}{|l|l|}
\hline System & Reference \\
\hline Polybutyl methacrylate with CNC; casting method & Ding et al. 2019 \\
\hline Bacterial cellulose; in-situ polymerization in the mixture & Faria et al. 2019 \\
\hline Copolymer with CNC and in-situ polymerization & Ouzas et al. 2019 \\
\hline Polyacrylamide with carboxymethylated NFC; film casting & Ryu et al. 2019 \\
\hline PMMA-grafted CNCs in acrylate copolymer; film casting & Zhang et al. 2019a,b \\
\hline
\end{tabular}


Since polymerization can be induced in-situ in a mixture by use of a free radical catalyst, the composite can be prepared from a solution, or from a melt. Although these listed studies show a potential role for very small cellulose-based particles, none of them compared particles of different size under the same conditions.

\section{Epoxy resin systems}

As epoxy resins can be prepared from a low-viscosity mixture, as well as having strong adhesion to polar surfaces, they can be regarded as ideal for many applications involving cellulosic reinforcements.

Effects of particle size were considered by He et al. (2016), who studied the reinforcement of an epoxy matrix with poplar wood flour and polyamine. With decreasing size of the wood flour particles, the mechanical properties initially increased but then showed a minor downward trend. The mechanisms of failure, based on microscopic observations, included both fiber breakage and fiber pullout, the latter indicating interfacial separation. The authors also reported evidence of agglomeration of the reinforcing material, especially at higher levels of addition. Longer fibers of similar width are more prone to agglomeration during stirring of a mixture (Hubbe 2017), and such agglomerates can serve as weak points in a composite. Thus, more extensive agglomeration is a possible reason to explain the minor fall-off in strength properties with increasing size of wood flour particles. Notably, Barczewski et al. (2019), who worked with ground sunflower husk and nut shells, found better strength performance with low-aspect-ratio particles. This was attributed to the fact that fibrous particles, having high aspect ratio, increased the viscosity of the mixture, leading to a porous structure of the composite.

Various other studies with epoxy resins showed promise for the preparation of nanocomposites. Nair et al. (2019) obtained promising results with NFC both in the glassy region and in the transition region of the matrix polymer. Saikia et al. (2019) also studied effects of NFC and reported typical dimensions of $40 \mathrm{~nm}$ thickness and $10 \mu \mathrm{m}$ length. Increased mechanical properties were observed, along with transparency to light. Given that epoxy-based composites are relatively easy to prepare with a wide range of reinforcements and a high tolerance for polar surfaces, it is to be hoped that a future study will explore the effects of particle size and length in greater depth.

\section{Phenol formaldehyde (PF) and related resin systems}

$\mathrm{PF}$ resins, as in the case of epoxies, have the advantage of relatively low viscosity prior to curing, making it possible to prepare composites with a wide range of reinforcements, some of which might be breakable under high shear or intolerant of the temperatures in a polymer melt. With respect to particle size, some of the most interesting results involving PF resin composites were those reported by Neelamana et al. (2013). These researchers compared banana fibers (fiber diameter $80 \mu \mathrm{m}$ ) with microfibers and nanofibers obtained by specific processing steps, including both chemical treatments and steam explosion. As shown in Fig. 10, the nanofibers were found to be about twice as effective as the other classes of particle, meaning that about half the dosage was needed to achieve a given increase in tensile strength.

Figure 11 shows corresponding results for flexural modulus. Here the nanofibers again showed the greatest effectiveness, but there was an interesting differentiation involving the two larger size classes of reinforcement. Notably, the relatively large unmodified banana fibers outperformed the intermediate class, the microfibers. The authors did not suggest any explanation. However, it seems likely that the complex, partly 
delaminated structure of woody material subjected to an initial steam explosion treatment would be susceptible to internal breakage, thus providing weak points at which cracks can be initiated.

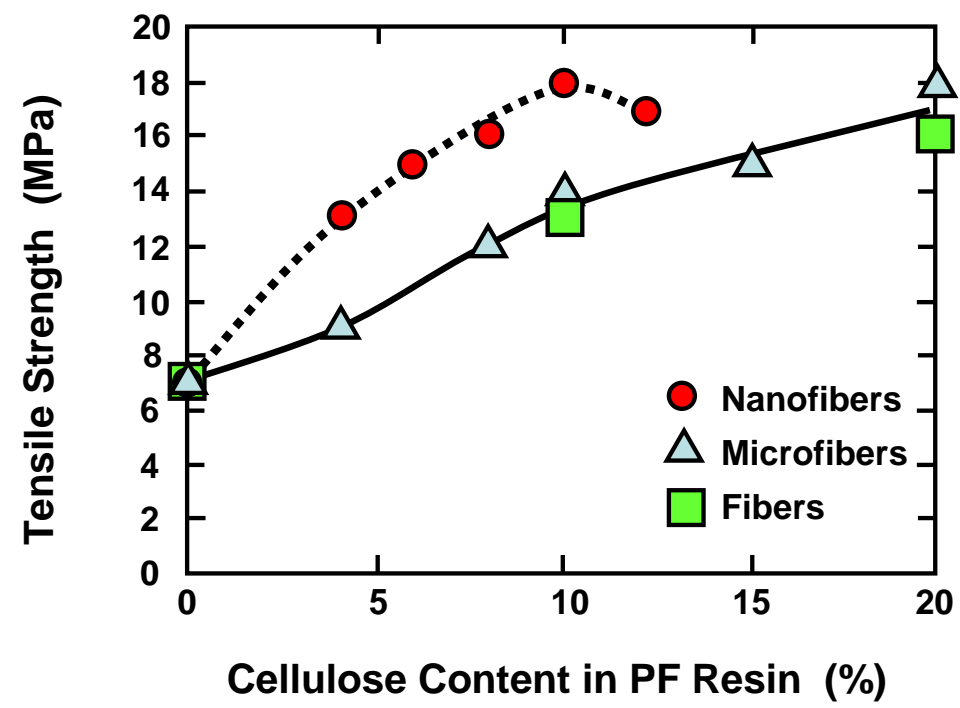

Fig. 10. Effects of three contrasting cellulosic particle reinforcements on the tensile strength of phenol-formaldehyde composites. Fibers = banana pseudo-stem; microfibers were obtained after soaking banana fibers in $2 \% \mathrm{NaOH}$, steam explosion, bleaching, washing, and drying; nanofibers were obtained from the microfibers with further eight-time steam explosion in the presence of oxalic acid. Figure plotted for the first time from the reported data (Neelamana et al. 2013)

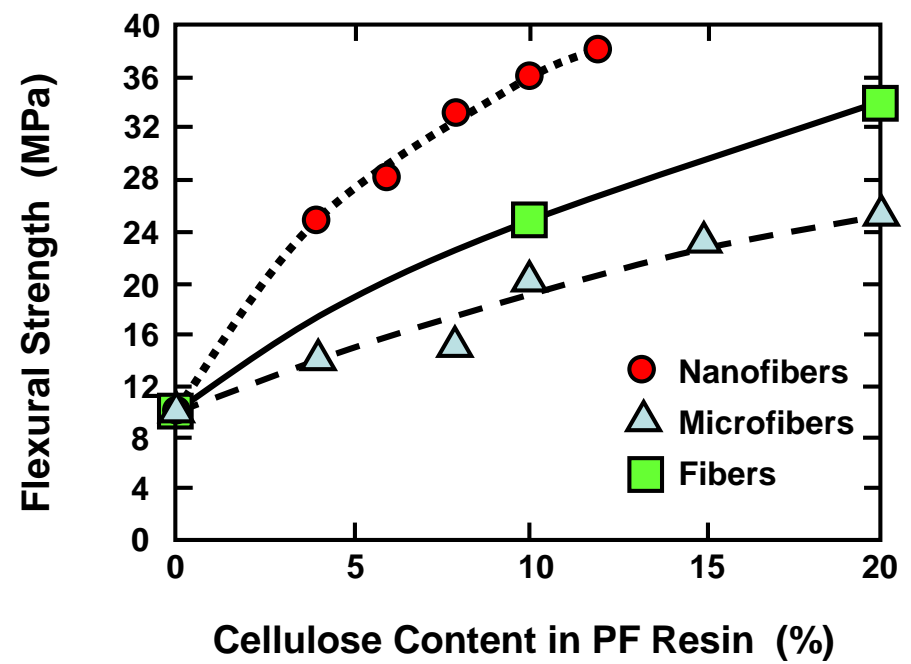

Fig. 11. Effects of three contrasting cellulosic particle reinforcements on the flexural strength of phenol-formaldehyde composites. Figure plotted for the first time from the reported data (Neelamana et al. 2013)

\section{Poly-(vinyl alcohol) (PVOH)}

Due to the generally hydrophilic nature of cellulose-based fibers, it is important to consider water-soluble polymers as a potential matrix. Among the synthetic water-soluble polymers, PVOH has been the most often studied for such purposes. Effects of particle 
size were considered by Jiang et al. (2018). Microfibrillated cellulose, having different attributes, was obtained from pure cellulose, holocellulose, and kraft pulp. For all three types of starting material, the tensile strength and elastic modulus both increased with decreasing size of the MFC. It was concluded that subjecting the cellulose to more prolonged wet-milling conditions improved its performance in the PVOH composites.

\section{Starch and other biopolymers}

Different varieties of starches are widely used in adhesives, and they tend to be cost-effective, particularly in cases where the resulting properties are sufficient to meet the application requirements. This includes many paper industry applications.

Soykeabkaew et al. (2012) compared the effects of bacterial cellulose (nano-sized) $v s$. ordinary jute fibers in starch composites prepared by film casting from aqueous solution. The highest strength results were achieved at a remarkably high loading of $50 \%$ bacterial cellulose. Relative to the strength of the starch by itself, the tensile strength was increased by a factor of about 200, and the tensile modulus was increased by an even greater factor. In general terms, these results are consistent with a very strong adhesion between the cellulose and the starch matrix, the weakness of the starch by itself, and the very high aspect ratio of the bacterial cellulose nanoparticles.

Ali et al. (2017) reported the effects of particle size of wheat and corn hull material in starch-based composite films. Only very weak dependencies on particle size were observed.

\section{Summary for studies with different sizes of particles in specified matrices}

Although studies comparing different sizes of cellulose-based particles under matched conditions in selected matrix systems yielded diverse results, some general trends can be identified from those cases discussed:

- As may be anticipated, experimental findings generally indicate that greater relative gains in elastic modulus can be achieved with softer matrix materials, especially starch, but also including HDPE.

- Advantages associated with longer fibers tended to be most pronounced relative to tensile and flexural modulus values. These advantages for longer fibers tended to be weaker or not present when considering tensile or flexural breaking strength testing.

- Compared to other forms of cellulose-based reinforcements, nanofibrillated cellulose often stands out as giving a superior contribution to strength of composites. This might be related to an expected high aspect ratio, typical of NFC.

- Relatively polar and in particular hydrogen-bonding matrix materials appear to offer a key advantage for cellulose-based reinforcements, since strong adhesion generally can be achieved in such cases without the need for any surface treatment of the reinforcement particles or addition of any coupling agent to the matrix.

\section{Disclaimers}

Before ending this review, it seems appropriate to draw attention to certain issues that might be considered in follow-up investigations. One issue, which was only dealt with to a minor degree in the present article, is the effects of different processing methods for 
composites. Another key issue concerns possible correlations involving the aspect ratios or diameters of reinforcing particles.

\section{Effects of processing options}

The properties of the neat HDPE employed in different studies showed very wide variations. It is not possible to know, when comparing results from such studies, whether the differences in their findings can be attributed to differences in the source materials employed or to differences in processing conditions, some as simple as the cooling rates used in injection molding. The processing conditions are of special concern when attempting to gain information about particle size effects from studies involving twin-screw extrusion, since the shear forces have been shown to be sufficient in many cases to shorten the fibers (Dickson et al. 2014; Soccalingame et al. 2015; Dickson and Sandquist 2018). In future research there are several potential strategies that could be considered in dealing with this issue. Perhaps the simplest is just to use relatively low-aspect-ratio reinforcing particles in such cases (Barczewski et al. 2019). Another approach is to essentially allow the high shear conditions associated with compounding and extrusion processes to do the work of size reduction and shortening. In such cases, if there is interest in investigating the effects of the length of reinforcing particles, the fiber length data needed for analysis could be obtained by microscopic imaging or by dissolving the matrix polymer, thus making it possible to recover the reinforcing particles and evaluate their size distributions. A third approach, in cases where relatively large gains in elastic modulus properties are sought, may be to employ manufacturing methods other than extrusion, e.g. solvent casting.

\section{Other sources of variability}

Another point to keep in mind, while considering the comparisons and regressions that have been made in the course of this article, is that there can be very large differences in results for nominally similar composite materials. Potential explanations for wide ranges of reported findings, when reporting results for the same matrix and reinforcement, can include differences in the matrix (including the modulus, degree of crystallinity, molecular mass, and impurities, etc.) and the reinforcing particles. In the latter case there may be unreported and hard-to-quantify differences in fiber damage, including curl and kink. In addition, the resulting orientation, as well as the extent of dispersion or flocculation in the composite, is likely to vary a lot, even within a given study. An analysis of the effects of such parameters on composite attributes would best be carried out in a dedicated experiment with well-characterized matrix materials and with fibers having relatively simple shapes.

\section{Selection of Particle Sizes for Different Composite Applications}

Though the regression analyses carried out in preparation of this article did not find any strong relationships between the particle size of reinforcing elements on composite properties, there still can be other reasons to strongly favor different ranges of size in different applications. Very small particles, including nanomaterials, may be strongly favored in applications where the material must flow through narrow orifices, such as nozzles for three-dimensional printing (Xu et al. 2015). Also, smaller reinforcements are desirable in cases where very smooth surfaces of plastic composites are a priority (Wechsler and Hiziroglu 2007). On the other hand, when producing large-scale materials at relatively low cost, the use of relative large cellulose-based reinforcements has the potential to save in preparation costs of the particles themselves, in addition to reducing 
any costs associated with compatibilizers to improve adhesion with the matrix (George et al. 2001; Belgacem and Gandini 2005; Kumar et al. 2011).

\section{CONCLUDING REMARKS}

As was noted in the Introduction, in preparing this review article the authors have attempted to determine whether there is an advantage of using large or small cellulosebased particles for reinforcement of various composites. In particular, the goal was to examine published evidence related to a possible strength advantage when nanocellulose reinforcements are used (Fu et al. 2008; Tanpichai and Wootthikanokkhan 2018). The overall findings from this review generally do not support the presumption that nanocellulose reinforcements offer a consistent and dependable advantage in terms of composite strength or modulus.

Having stated the general findings drawn from a "big picture" view of results from numerous studies, it is also possible to draw some other lessons from the research that was considered in preparing this article.

- For the reinforcement of low-surface-energy plastics such as HDPE and polypropylene, where it has been shown that either surface treatment of the cellulosic particles (e.g. silane treatment or esterification) or addition of a coupling agent to the plastic before compounding and extrusion (e.g. MAPE), the weight of the evidence favors the use of relatively large particles, within the range of practicality. The upper end of that practical range might be related to effects on surface roughness or appearance of a composite, process limitations due to the sizes of nozzles, etc., and the possibility that too-large cellulosic particles might function as sites of initiation of cracks that are big enough to precipitate early failure in tensile tests or flexural strength tests.

- For the reinforcement of polar matrix materials such as epoxy resin, starch, PLA, etc., which bond relatively strongly to unmodified cellulosic surfaces, the motivation to favor larger particle sizes for reinforcements seems less strong. Thus, it is easier to justify serious consideration of a range of different particle sizes, depending on the details of the property objectives for the composites.

- Both economics and sustainability principles generally favor usage of plant-based materials with the least amount of modification that is required to meet one's objectives. Such principles generally favor using cellulosic material in the largest dimensions consistent with both the processing limitations and the required product attributes.

\section{ACKNOWLEDGEMENTS}

The authors thank the following individuals who studied an earlier draft and provided suggestions and corrections: Parameswaranpillai Jyotishkumar, Research Professor, King Mongkut's University of Technology North Bangkok (KMUTNB), 1518 Pracharat 1, Wongsawang Road, Bangsue, Bangkok, 10800, Thailand; David Harper, Univ Tennessee, Ctr Renewable Carbon, 2506 Jacob Dr, Knoxville, TN 37996 USA; and Salim 
Hiziroglu, Oklahoma State Univ, Dept Nat Resource Ecol \& Management, Stillwater, OK 74078 USA.

\section{REFERENCES CITED}

Abba, H. A., Zahari, I. N., Sapuan, S. M., and Leman, Z. (2017). "Characterization of millet (Pennisetum glaucum) husk fiber (MHF) and its use as filler for high density polyethylene (HDPE) composites," BioResources 12(4), 9287-9301. DOI:

10.15376/biores.12.4.9287-9301

Agayev, S., and Ozdemir, O. (2019). "Fabrication of high density polyethylene composites reinforced with pine cone powder: Mechanical and low velocity impact performances," Mater. Res. Expr. 6(4), article no. 045312. DOI: 10.1088/20531591/aafc42

Aggarwal, P. K., Chauhan, S., Raghu, N., Karmarkar, S., Shashidhar, G. M. (2013). "Mechanical properties of bio-fibers-reinforced high-density polyethylene composites: Effect of coupling agents and bio-fillers," J. Reinf. Plastics Composites 32(22), 1722-1732. DOI: 10.1177/0731684413500545

Aji, I. S., Zainudin, E. S., Khalina, A., Sapuan, S. M., and Khairul, M. D. (2011). "Studying the effect of fiber size and fiber loading on the mechanical properties of hybridized kenaf/PALF-reinforced HDPE composite," J. Reinf. Plastics Composites 30(6), 546-553. DOI: 10.1177/0731684411399141

Akter, T., Nur, H. P., Sultana, S., Islam, M. R., Abedin, M. J., and Islam, Z. (2018). "Evaluation of mechanical properties of both benzoyl peroxide treated and untreated teak sawdust reinforced high density polyethylene composites," Cellulose 25(2), 1171-1184. DOI: 10.1007/s10570-017-1620-3

Alavi, F., Behravesh, A. H., and Mirzaei, M. (2013). "In-situ observation of fracture mechanism of wood-plastic composites in tension," Composite Interfaces 20(3), 211220. DOI: $10.1080 / 15685543.2013 .770684$

Ali, A., Yu, L., Liu, H. S., Khalid, S., Meng, L. H., and Chen, L. (2017). "Preparation and characterization of starch-based composite films reinforced by corn and wheat hulls," J. Appl. Polym. Sci. 134(32), article no. 45159. DOI: 10.1002/app.45159

Al-Maharma, A. Y., and Sendur, P. (2019). "Review of the main factors controlling the fracture toughness and impact strength properties of natural composites," Mater. Res. Expr. 6(2), article no. 022001. DOI: 10.1088/2053-1591/aaec28

Alsewailem, F. D., and Binkhder, Y. A. (2010.). "Preparation and characterization of polymer/date pits composites," J. Reinf. Plastics Composites 29(11), 1743-1749. DOI: 10.1177/0731684409337339

Ashok, B., Obi Reddy, K., Feng, H. T., and Varada Rajulu, A. (2019). "Preparation and properties of cellulose/Thespesia lampas microfiber composite films," Int. J. Biol. Macromol. 127, 153-158. DOI: 10.1016/j.ijbiomac.2019.01.041

Ashori, A., and Nourbakhsh, A. (2010). "Reinforced polypropylene composites: Effects of chemical compositions and particle size," Bioresour. Technol. 101(7), 2515-2519. DOI: 10.1016/j.biortech.2009.11.022

Bajwa, D. S., Adhikari, S., Shojaeiarani, J., Bajwa, S. G., Pandey, P., and Shanmugam, S. R. (2019). "Characterization of bio-carbon and ligno-cellulosic fiber reinforced biocomposites with compatibilizer," Construc. Building Mater. 204, 193-202. DOI: 10.1016/j.conbuildmat.2019.01.068 
Barczewski, M., Salasinska, K., and Szulc, J. (2019). "Application of sunflower husk, hazelnut shell and walnut shell as waste agricultural fillers for epoxy-based composites: A study into mechanical behavior related to structural and rheological properties," Polymer Testing 75, 1-11. DOI: 10.1016/j.polymertesting.2019.01.017

Belgacem, M. N., and Gandini, A. (2005). "The surface modification of cellulose fibres for use as reinforcing elements in composite materials," Composite Interfaces 12, 4175. DOI: $10.1163 / 1568554053542188$

Ben Mbarek, T., Robert, L., Sammouda, H., Charrier, B., Orteu, J. J., and Hugot, F. (2013). "Effect of acetylation and additive on the tensile properties of wood fiberhigh-density polyethylene composite," J. Reinf. Plastics Composites 32(21), 16461655. DOI: $10.1177 / 0731684413505256$

Berube, D. M. (2006). Nano-hype: The Truth behind the Nanotechnology Buzz, Prometheus Books, Amherst, NY.

Biswas, K., Khandelwal, V., and Maiti, S. N. (2019). "Mechanical and thermal properties of teak wood flour/starch filled high density polyethylene composites," Int. Polymer Processing 34(2), 209-218. DOI: 10.3139/217.3640

Bolin, C. A., and Smith, S. (2011). "Life cycle assessment of ACQ-treated lumber with comparison to wood plastic composite decking," J. Cleaner Prod. 19(6-7), 620-629. DOI: $10.1016 /$ j.jclepro.2010.12.004

Borah, J. S., and Kim, D. S. (2016). "Recent development in thermoplastic/wood composites and nanocomposites: A review," Korean J. Chem. Eng. 33(11), 30353049. DOI: $10.1007 / \mathrm{s} 11814-016-0183-6$

Boran, S. (2016). "Mechanical, morphological, and thermal properties of nutshell and microcrystalline cellulose filled high-density polyethylene composites," BioResources 11(1), 1741-1752. DOI: 10.15376/biores.11.1.1741-1752

Boran, S., Kiziltas, A., Kiziltas, E. E., and Gardner, D. J. (2016). "Characterization of ultrafine cellulose-filled high density polyethylene composites prepared using different compounding methods," BioResources 11(4), 8178-8199. DOI: 10.15376/biores.11.4.8178-8199

Bouafif, H., Koubaa, A., Perre, P., and Cloutier, A. (2010). "Effects of composite processing methods on wood particle development and length distribution: Consequences on mechanical properties of wood-thermoplastic composites," Wood Fiber Sci. 42(1), 62-70.

Butron, A., Llorente, O., Fernandez, J., Meaurio, E., and Sarasua, J. R. (2019). "Morphology and mechanical properties of poly(ethylene brassylate)/cellulose nanocrystal composites," Carbohydr. Polym. 221, 137-145. DOI: 10.1016/j.carbpol.2019.05.091

Campilho, R. D. S. G. (2016). "Introduction to natural fiber composites," Natural Fiber Composites, R. D. S. G. Campilho (ed.), CRC Press, Tayor and Francis, pp. 1-34.

Cavdar, A. D., Mengeloglu, F., Karakus, K., and Tomak, E. D. (2014). "Effect of chemical modification with maleic, propionic, and succinic anhydrides on some properties of wood flour filled HDPE composites," BioResources 9(4), 6490-6503. DOI: $10.15376 /$ biores.9.4.6490-6503

Cetin, N. S., Cetin, N. O., and Harper, D. P. (2015). "Vinyl acetate-modified microcrystalline cellulose-reinforced HDPE composites prepared by twin-screw extrusion," Turkish J. Agric. Forestry 39(1), 39-47. DOI: 10.3906/tar-1402-115 
Chan, C. M., Vandi, L. J., Pratt, S., Halley, P., Richardson, D., Werker, A., and Laycock, B. (2018). "Composites of wood and biodegradable thermoplastics: A review," Polymer Rev. 58(3), 444-494. DOI: 10.1080/15583724.2017.1380039

Chang, F. C., Kadla, J. F., and Lam, F. (2016). "The effects of wood flour content and coupling agent on the dynamic mechanical and relaxation properties of wood-plastic composites," Eur. J. Wood Wood Prod. 74(1), 23-30. DOI: 10.1007/s00107-0150962-5

Chen, B., Luo, Z. F., Cai, T. T., Cai, D., Zhang, C. W., Qin, P. Y., and Cao, H. (2018). "The effect of corn varieties on the production of fiber-reinforced high-density polyethylene composites," Biomass Conver. Biorefin. 8(4), 953-963. DOI: 10.1007/s13399-018-0337-3

Chen, F., Han, G. P., Li, Q. D., Gao, X., and Cheng, W. L. (2017). "High-temperature hot air/silane coupling modification of wood fiber and its effect on properties of wood fiber/HDPE composites," Materials 10(3), article no. 286. DOI: 10.3390/ma10030286

Chen, H. C., Chen, T. Y., and Hsu, C. H. (2006). "Effects of wood particle size and mixing ratios of HDPE on the properties of the composites," Holz Roh Werkst. 64(3), 172-177. DOI: $10.1007 / \mathrm{s} 00107-005-0072-\mathrm{x}$

Chen, R. D., Huang, C. F., and Hsu, S. H. (2019). "Composites of waterborne polyurethane and cellulose nanofibers for 3D printing and bioapplications," Carbohydr. Polym. 212, 75-88. DOI: 10.1016/j.carbpol.2019.02.025

Cisneros-Lopez, E. O., Anzaldo, J., Fuentes-Talavera, F. J., Gonzalez-Nunez, R., Robledo-Ortiz, J. R., and Rodrigue, D. (2017). "Effect of agave fiber surface treatment on the properties of polyethylene composites produced by dry-blending and compression molding," Polym. Composites 38(1), 96-104. DOI: 10.1002/pc.23564

Crosky, A., Soatthiyanon, N., Ruys, D., Meatherall, S., and Potter, S. (2014). "Thermoset matrix natural fibre-reinforced composites," in: Natural Fibre Composites: Materials, Processes and Properties, A. Hodzic and R. Shanks (eds.), Woodhead Publ., Ser. In Composites Science and Engineering, Issue 47, pp. 233-270. DOI: 10.1533/9780857099228.2.233

Cui, Y., Lee, S., Noruziaan, B., Cheung, M., and Tao, J. (2008). "Fabrication and interfacial modification of wood/recycled plastic composite materials," Composites Part A - Appl. Sci. Manufac. 39(4), 655-661. DOI: 10.1016/j.compositesa.2007.10.017

de Assis, C.A., Houtman, C., Phillips, R., Bilek, E. M., Rojas, O. J., Pal, L., Peresin, M. S., Jameel, H., and Gonzalez, R. (2017). "Conversion economics of forest biomaterials: risk and financial analysis of CNC manufacturing," Biofuels Bioprod. Bioref-BIOFPR 11(4), 682-700. DOI: 10.1002/bbb.1782

Delgado-Aguilar, M., Gonzalez, I., Tarres, Q., Alcala, M., Pelach, M. A., and Mutje, P. (2015). "Approaching a low-cost production of cellulose nanofibers for papermaking applications,” BioResources 10(3), 5345-5355. DOI: 10.15376/biores.10.3.5345-5355

de Macedo, J. R. N., dos Santos, D. J., Rosa, D. D. (2019). "Poly(lactic acid)thermoplastic starch-cotton composites: Starch-compatibilizing effects and composite biodegradability," J. Appl. Polym. Sci. 136(21), article no. 47490. DOI: 10.1002/app. 47490

Dhakal, H. N., MacMullen, J., and Zhang, Z. Y. (2015). "Testing and characterization of natural fiber-reinforced composites," in: Natural Fiber Composites, R. D. S. G. Campilho (ed.), CRC Press, Boca Raton, FL. 
Dickson, A. R., Even, D., Warnes, J. M., and Fernyhough, A. (2014). "The effect of reprocessing on the mechanical properties of polypropylene reinforced with wood pulp, flax or glass fibre," Composites Part A - Appl. Sci. Manufac. 61, 258-267. DOI: 10.1016/j.compositesa.2014.03.010

Dickson, A. R., and Sandquist, D. (2018). "Mode of wood fibre breakage during thermoplastic melt processing," Composites Part A - Appl. Sci. Manufac. 112, 496503. DOI: 10.1016/j.compositesa.2018.07.004

Di Giuseppe, E., Castellani, R., Budtova, T., and Vergnes, B. (2017). "Lignocellulosic fiber breakage in a molten polymer. Part 2. Quantitative analysis of the breakage mechanisms during compounding," Composites Part A-Appl. Sci. Manuf. 95, 31-39. DOI: 10.1016/j.compositesa.2016.12.011

DiLoreto, E., Haque, E., Berman, A., Moon, R. J., and Kalaitzidou, K. (2019). "Freeze dried cellulose nanocrystal reinforced unsaturated polyester composites: challenges and potential," Cellulose 26(7), 4391-4403. DOI: 10.1007/s10570-019-02377-1

Ding, C. X., Cai, C. Y., Yin, L. X., Wu, Q. L., Pan, M. Z., and Mei, C. T. (2019). "Mechanically adaptive nanocomposites with cellulose nanocrystals: Strain-field mapping with digital image correlation," Carbohyd. Polym. 211, 11-21. DOI: 10.1016/j.carbpol.2019.01.098

Durmus, A., Ozcan, M., and Aydin, I. (2019). "Quantifying effects of compositional variations on microstructural properties of polypropylene-wood fiber composites by melt rheology and tensile test data," J. Composite Mater. 53(4), 503-514. DOI: $10.1177 / 0021998318786792$

Eichhorn, S. J., Dufresne, A., Aranguren, M., Marcovich, N. E., Capadona, J. R., Rowan, S. J., Weder, C., Thielemans, W., Roman, M., Renneckar, S., et al. (2010). "Review: Current international research into cellulose nanofibres and nanocomposites," $J$. Mater. Sci. 45(1), 1-33. DOI: 10.1007/s10853-009-3874-0

Elloumi, A., Makhlouf, M., Elleuchi, A., and Bradai, C. (2016). "Deinking sludge: A new biofiller for HDPE composites," Polym. Plast. Technol. Eng. 55(10), 1012-1020. DOI: $10.1080 / 03602559.2015 .1132432$

Essabir, H., Hilali, E., Elgharad, A., El Minor, H., Imad, A., Elamraoui, A., and Al Gaoudi, O. (2013). "Mechanical and thermal properties of bio-composites based on polypropylene reinforced with nut-shells of argan particles," Mater. Design 49, 442448. DOI: 10.1016/j.matdes.2013.01.025

Fang, L., Xiong, X. Q., Wang, X. H., Chen, H., and Mo, X. F. (2017). "Effects of surface modification methods on mechanical and interfacial properties of high-density polyethylene-bonded wood veneer composites," J. Wood Sci. 63(1), 65-73. DOI: 10.1007/s10086-016-1589-9

Farah, S., Anderson, D. G., and Langer, R. (2016). "Physical and mechanical properties of PLA, and their functions in widespread applications - A comprehensive review," Adv. Drug Deliv. Rev. 107, 367-392. DOI: 10.1016/j.addr.2016.06.012

Faria, M., Vilela, C., Mohammadkazemi, F., Silvestre, A. J. D., Freire, C. S. R., and Cordeiro, N. (2019). "Poly(glycidyl methacrylate)/bacterial cellulose nanocomposites: Preparation, characterization and post-modification," Int. J. Bio. Macromol. 127, 618-627. DOI: 10.1016/j.ijbiomac.2019.01.133

Farsi, M. (2012). "Effect of fiber surface modification on the thermo-mechanical behaviour of wood-polymer composite," Asian J. Chem. 24(6), 2775-2779.

Fathi, B., Foruzanmehr, M., Elkoun, S., and Robert, M. (2019). "Novel approach for silane treatment of flax fiber to improve the interfacial adhesion in flax/bio epoxy 
composites," J. Composite Mater. 53(16), 2229-2238. DOI:

10.1177/0021998318824643

Fonseca-Valero, C., Ochoa-Mendoza, A., Arranz-Andres, J., and Gonzalez-Sanchez, C. (2015). "Mechanical recycling and composition effects on the properties and structure of hardwood cellulose-reinforced high density polyethylene eco-composites," Composites Part A - Appl. Sci. Manufac. 69, 94-104. DOI:

10.1016/j.compositesa.2014.11.009

Fortunati, E., Yang, W., Luzi, F., Kenny, J., Torre, L., and Puglia, D. (2016). "Lignocellulosic nanostructures as reinforcement in extruded and solvent casted polymeric nanocomposites: An overview," Eur. Polym. J. 80, 295-316. DOI: 10.1016/j.eurpolymj.2016.04.013

Frone, A. N., Berlioz, S., Chailan, J. F., Panaitescu, D. M., and Donescu, D. (2011). “Cellulose fiber-reinforced polylactic acid," Polym. Compos. 32(6), 976-985. DOI: $10.1002 /$ pc. 21116

Fu, S. Y., Feng, X. Q., Lauke, B., and Mai, Y. W. (2008). 'Effects of particle size, particle/matrix interface adhesion and particle loading on mechanical properties of particulate-polymer composites," Composites Part B - Eng. 39(6), 933-961. DOI: 10.1016/j.compositesb.2008.01.002

Gallagher, L. W., and McDonald, A. G. (2013). "The effect of micron sized wood fibers in wood plastic composites," Maderas - Ciencia y Technol. 15(3), 357-374. DOI: 10.4067/S0718-221X2013005000028

Gao, H. H., and Qiang, T. (2017). "Fracture surface morphology and impact strength of cellulose/PLA composites," Mater. 10(6), article no. 624. DOI: 10.3390/ma10060624

Gao, X., Li, Q. D., Cheng, W. L., Han, G. P., and Xuan, L. H. (2017). "High temperature and pressurized steaming/silane coupling co-modification for wood fibers and its effect on the properties of wood fiber/HDPE composites," Macromol. Res. 25(2), 141-150. DOI: 10.1007/s13233-017-5024-X

Gao, X., Lin, L., Pang, J. Y., Chen, F., and Li, Q. D. (2019). "Effects of impulse-cyclone drying and silane modification on the properties of wood fiber/HDPE composite material," Carbohyd. Polym. 207, 343-351. DOI: 10.1016/j.carbpol.2018.11.078

Gaugler, M., Luedtke, J., Grigsby, W. J., and Krause, A. (2019). “A new methodology for rapidly assessing interfacial bonding within fibre-reinforced thermoplastic composites," Int. J. Adhesion Adhesives 89, 66-71. DOI:

10.1016/j.ijadhadh.2018.11.010

George, J., Sreekala, M. S., and Thomas, S. (2001). "A review of interface modifications and characterization of natural fibre reinforced plastic composites," Polym. Eng. Sci. 41(9), 1471-1485. DOI: 10.1002/pen.10846

Gindl, W. (2009). "Cellulose fibril- and whisker-reinforced polymer nanocomposites," in: Recent Advances in Polymer Nanocomposites, S. Thomas, G. E. Zaikov, and S. V. Valsaraj (eds.), Brill, pp. 269-284.

Gomes, V. N. C., Carvalho, A. G., Furukava, M., Medeiros, E. S., Colombo, C. R., Melo, T. J. A., Araujo, E. M., Morais, D. D. S., Ueki, M. M., Paskocimas, C. A., and others. (2018). "Characterization of wood plastic composite based on HDPE and cashew nutshells processed in a thermokinetic mixer," Polym. Composites 39(8), 2662-2673. DOI: $10.1002 /$ pc. 24257

Gozdecki, C., and Wilczynski, A. (2015). "Effects of wood particle size and test specimen size on mechanical and water resistance properties of injected wood-high density polyethylene composite," Wood Fiber Sci. 47(4), 365-374. 
Grigsby, W. J., Gager, V., Recabar, K., Krause, A., Gaugler, M., and Luedtke, J. (2019). "Visualising wood-polymer interfaces developed between wood and poly(lactic acid) in sandwich laminate composites," Fibers 7(2), article no. 15. DOI: 10.3390/fib7020015.

Grison, K., Pistor, V., Scienza, L. C., and Zattera, A. J. (2016). "The physical perspective on the solid and molten states associated with the mechanical properties of ecofriendly HDPE/Pinus taeda wood-plastic composites," J. Appl. Polym. Sci. 133(3), article no. 42887. DOI: 10.1002/app.42887

He, S. S., Liu, T., and Di, M. W. (2016). "Preparation and properties of wood flour reinforced lignin-epoxy resin composite," BioResources 11(1), 2319-2333. DOI: 10.15376/biores.11.1.2319-2333

Hemmasi, A. H. (2013). "Study on the tensile and impact properties of bagasse flour/recycled high-density polyethylene composite," Asian J. Chem. 25(13), 76457646. DOI: 10.14233/ajchem.2013.14981

Hillig, E., Bobadilla, I., Zattera, A. J., de Lima, E. A. A., and Marchesan, R. (2017). "Influence of coconut shell addition on physico-mechanical properties of wood plastic composites," Revista Arvore 41(4), article no. UNSP e410412. DOI: 10.1590/1806-90882017000400012

Hillig, E., Iwakiri, S., Haselein, C. R., Bianchi, O., and Hillig, D. M. (2011). "Characterization of composites made of HDPE and furniture industry sawdust. Part II: Double-screw extrusion," Ciencia Florestal 21(2), 335-347.

Hosseini, S. B., Hedjazi, S., and Jamalirad, L. (2017). "Investigation on physical and mechanical properties of pulp-plastic composites from bagasse," Wood Mater. Sci. Eng. 12(5), 279-287. DOI: 10.1080/17480272.2016.1175505

Hou, Y. S., Yan, S., Guo, X., and Di, M. W. (2017). "Combined surface treatment of polyethylene wood-plastic composites to achieve rapid bonding with desired adhesion properties," BioResources 12(3), 6434-6445. DOI: 10.15376/biores.12.3.6434-6445

Huang, L., Mu, B. S., Yi, X., Li, S. J., and Wang, Q. W., (2018). "Sustainable use of coffee husks for reinforcing polyethylene composites," J. Polym. Environ. 26(1), 4858. DOI: 10.1007/s10924-016-0917-x

Hubbe, M. A. (2017). "Hybrid filler (cellulose/noncellulose) reinforced nanocomposites," in: Handbook of Nanocellulose and Cellulose Nanocomposites, Vol. 1, H.

Kargarzadeh, I. Ahmad, S. Thomas, and A. Dufresne (eds.), Wiley-VCH, Ch. 8, pp. 273-299.

Hubbe, M. A. (2018). "Think big: The case against relying just on nanocellulose to reinforce plastics composites," presented at Pan Pacific Fibre Value Chain Conference 2018, Bioproducts Manufacturing Symposium, APPITA, Rotorua, New Zealand.

Hubbe, M. A., Rojas, O. J., and Lucia, L. A. (2015). "Green modification of surface characteristics of cellulosic materials at the molecular or nano scale: A review," BioResources 10(3), 6095-6229. DOI: 10.15376/biores.10.3.Hubbe

Hubbe, M. A., Rojas, O. J., Lucia, L. A., and Sain, M. (2008). "Cellulosic nanocomposites, A review," BioResources 3(3), 929-980.

Hubbe, M. A., Tayeb, P., Joyce, M., Tyagi, P., Kehoe, M., Dimic-Misic, K., and Pal, L. (2017). "Rheology of nanocellulose-rich aqueous suspensions: A Review," BioResources 12(4), 9556-9661.

Hung, K. C., Wu, T. L., Chen, Y. L., and Wu, J. H. (2016). "Assessing the effect of wood acetylation on mechanical properties and extended creep behavior of wood/recycled- 
polypropylene composites," Construc. Building Mater. 108, 139-145. DOI:

10.1016/j.conbuildmat.2016.01.039

Igarashi, Y., Sato, A., Okumura, H., Nakatsubo, F., and Yano, H. (2018). "Manufacturing process centered on dry-pulp direct kneading method opens a door for commercialization of cellulose nanofiber reinforced composites," Chem. Eng. J. 354, 563-568. DOI: 10.1016/j.cej.2018.08.020

Ihamouchen, C., Djidjelli, H., Boukerrou, A., Fenouillot, F., and Barres, C. (2019). "Mechanical properties and thermal behavior of polyethylene composites reinforced with fibers lignocellolusiques," Materiaux Techn. 106(6), article no. 601. DOI: $10.1051 /$ mattech/2018064

Ikladious, N. E., Shukry, N., El-Kalyoubi, S. F., Asaad, J. N., Mansour, S. H., Tawfik, S. Y., and Abou-Zeid, R. E. (2019). "Eco-friendly composites based on peanut shell powder / unsaturated polyester resin," Proceedings of The Institution of Mechanical Engineers Part L - J. Mater. Design Appl. 233(5), 955-964. DOI:

$10.1177 / 1464420717722377$

Ismail, H., and Shafiq, M. D. (2016). "The comparison of properties of (rubber tree seed shell flour)-filled polypropylene and high-density polyethylene composites," J. Vinyl Additive Technol. 22(2), 91-99. DOI: 10.1002/vnl.21409

Jaya, H., Omar, M. F., Akil, H. M., Ahmad, Z. A., and Zulkepli, N. N. (2016). "Effect of particle size on mechanical properties of sawdust-high density polyethylene composites under various strain rates," BioResources 11(3), 6489-6504. DOI: 10.15376/biores.11.3.6489-6504

Jia, Q., Yu, C. H., Jin, J. Y., Sarsaiya, S., and Chen, J. S. (2018). "Mechanical properties of polyethylene composites filled with willow (Salix babylonica L.) bark-boring insect dust," J. Biobased Mater. Bioenergy 12(6), 540-544. DOI: 10.1166/jbmb.2018.1802

Jiang, L. Y., Li, Y., Ma, B. L., Ding, H. J., Su, S. P., and Xiong, C. D. (2018). "Effect of bamboo fiber length on mechanical properties, crystallization behavior, and in vitro degradation of bamboo fiber/nanohydroxyapatite/poly(lactic-co-glycolic) composite," Indust. Eng. Chem. Res. 57(13), 4585-4591. DOI: 10.1021/acs.iecr.7b05354

Jenkins, C. H. (ed.) (1998). Manual on Experimental Methods for Mechanical Testing of Composites, $2^{\text {nd }}$ Ed., Fairmont Press, Lilburn, GA.

John, R., Schreiter, K., Trommler, K., Siegel, C., Wagenfuhr, A., and Spange, S. (2019). "Maleic anhydride copolymers as adhesion-promoting reagent in wood veneer/biopolyethlyene composite materials," Polym. Composites 40(5), 1979-1988. DOI: $10.1002 /$ pc. 24974

Kajaks, J., Kalnins, K., and Naburgs, R. (2018). "Wood plastic composites (WPC) based on high-density polyethylene and birch wood plywood production residues," Int. Wood Prod. J. 9(1), 15-21. DOI: 10.1080/20426445.2017.1410997

Kajaks, J., Zagorska, A., and Mezinskis, A. (2015). "Some exploitation properties of wood plastic composites (WPC), based on high density polyethylene and timber industry waste," Mater. Sci. - Mediagotyra 21(3), 396-399. DOI: 10.5755/j01.ms.21.3.7283

Kalaprasad, G., Joseph, K., Thomas, S., and Pavithran, C. (1997). "Theoretical modelling of tensile properties of short sisal fibre-reinforced low-density polyethylene composites," J. Mater. Sci. 32(16), 4261-4267. DOI: 10.1023/A:1018651218515

Kangas, H., Lahtinen, P., Sneck, A., Saariaho, A. M., Laitinen, O., and Hellen, E. (2014). "Characterization of fibrillated celluloses. A short review and evaluation of 
characteristics with a combination of methods," Nordic Pulp Paper Res. J. 29(1), 129-143.

Kaymakci, A., and Ayrilmis, N (2014). "Waste chestnut shell as a source of reinforcing fillers for polypropylene composites," J. Thermoplastic Compos. Mater. 27(8), 10541064. DOI: $10.1177 / 0892705712461648$

Kettunen, P. O. (2006). Wood Structure and Properties, Trans Tech Publ. Ltd., Enfield,

Khamedi, R., Hajikhani, M., and Ahmaditabar, K. (2019). "Investigation of maleic anhydride effect on wood plastic composites behavior," J. Composite Materials 53(14), 1955-1962. DOI: 10.1177/0021998318816769

Khonsari, A., Taghiyari, H. R., Karimi, A., and Tajvidi, M. (2015). "Study on the effects of wood flour geometry on physical and mechanical properties of wood-plastic composites," Maderas - Cienca y Technol. 17(3), 545-558. DOI: 10.4067/S0718221X2015005000049

Kilinc, A. C., Atagur, M., Ozdemir, O., Sen, I., Kucukdogan, N., Sever, K., Seydibeyoglu, O., Sarikanat, M., and Seki, Y. (2016). "Manufacturing and characterization of vine stem reinforced high density polyethylene composites," Composites Part B - Eng. 91, 267-274. DOI: 10.1016/j.compositesb.2016.01.033

Kowalczyk, M., Piorkowska, E., Kulpinski, P., and Pracella, M. (2011). "Mechanical and thermal properties of PLA composites with cellulose nanofibers and standard size fibers," Composites Part A - Appl. Sci. Manufac. 42(10), 1509-1514. DOI: 10.1016/j.compositesa.2011.07.003

Krishnaiah, P., Ratnam, C. T., and Manickam, S. (2017). "Enhancements in crystallinity, thermal stability, tensile modulus and strength of sisal fibres and their PP composites induced by the synergistic effects of alkali and high intensity ultrasound (HIU) treatments," Ultrasonic Sonochem. 34, 729-742. DOI:

10.1016/j.ultsonch.2016.07.008

Ku, H., Wang, H., Pattarachaiyakoop, N., and Trada, M. (2011). "A review on the tensile properties of natural fiber reinforced polymer composites," Composites Part B - Eng. 42(4), 856-873. DOI: 10.1016/j.compositesb.2011.01.010

Kumar, V., Tyagi, L., and Sinha, S. (2011). "Wood flour-reinforced plastic composites: A review," Rev. Chem. Eng. 27(5-6), 253-264. DOI: 10.1515/REVCE.2011.006

Kundu, P. P., Biswas, J., Kim, H., and Choe, S. (2003). "Influence of film preparation procedures on the crystallinity, morphology and mechanical properties of LLDPE films," Eur. Polym. J. 39(8), 1585-1593. DOI: 10.1016/S0014-3057(03)00056-9

Lavoine, N., Desloges, I., Dufresne, A., and Bras, J. (2012). "Microfibrillated cellulose: Its barrier properties and applications in cellulosic materials: A review," Carbohyd. Polym. 90, 735-764. DOI: 10.1016/j.carbpol.2012.05.026

Lee, K. Y., Buldum, G., Mantalaris, A., and Bismarck, A. (2014). "More than meets the eye in bacterial cellulose: Biosynthesis, bioprocessing, and applications in advanced fiber composites," Macromol. Biosci. 14(1), 10-32. DOI: 10.1002/mabi.201300298

Lewandowska, A. E., Inai, N. H., Ghita, O. R., and Eichhorn, S. J. (2018). "Quantitative analysis of the distribution and mixing of cellulose nanocrystals in thermoplastic composites using Raman chemical imaging," RSC Advan. 8(62), 35831-35839. DOI: $10.1039 / \mathrm{c} 8 \mathrm{ra06674d}$

Lewin, M., and Goldstein, I. S. (1991). Wood Structure and Composition, CRC Press, New York. 
Li, J. J., Li, D. G., Song, Z. Q., Shang, S. B., and Guo, Y. (2016). "Preparation and properties of wood plastic composite reinforced by ultralong cellulose nanofibers," Polymer Compos. 37(4), 1206-1215. DOI: 10.1002/pc.23285

Li, J. J., Song, Z. Q., Li, D. G., Shang, S. B., and Guo, Y. (2014). “Cotton cellulose nanofiber-reinforced high density polyethylene composites prepared with two different pretreatment methods," Indust. Crops Prod. 59, 318-328. DOI: 10.1016/j.indcrop.2014.05.033

Li, S. H., Wang, C. P., Chu, F. X., Xia, J. L., and Xu, Y. Z. (2013). 'Effects of compatibilizers on composites of acorn shell powder and low density polyethylene," BioResources 8(4), 5817-5825. DOI: 10.15376/biores.8.4.5817-5825

Li, Y. L. (2012). "Effect of coupling agent concentration, fiber content, and size on mechanical properties of wood/HDPE composites," Int. J. Polym. Mater. 61(11), 882890. DOI: $10.1080 / 00914037.2011 .617338$

Lightsey, G. R., Short, P. H., and Sinha, V. K. K. (1977). "Low-cost polyolefin composites containing pulp-mill wood residue," Polym. Eng. Sci. 17(5), 305-310. DOI: 10.1002/pen.760170507

Liu, T., Lei, Y., Wang, Q. W., Lee, S. Y., and Wu, Q. L. (2013). "Effect of fiber type and coupling treatment on properties of high-density polyethylene/natural fiber composites," BioResources 8(3), 4619-4632. DOI: 10.15376/biores.8.3.4619-4632

Liu, Y. C., Lv, X. M., Bao, J. L., Xie, J., Tang, X., Che, J. J., Ma, Y. H., and Tong, J. (2019). "Characterization of silane treated and untreated natural cellulosic fibre from corn stalk waste as potential reinforcement in polymer composites," Carbohydr. Polym. 218, 179-187. DOI: 10.1016/j.carbpol.2019.04.088

Louvier-Hernandez, J. F., Garcia-Bustos, E., Hernandez-Navarro, C., Mendoza-Leal, G., Alcaraz-Caracheo, L. A., Navarrete-Damian, J., and Garcia-Rodriguez, F. J. (2018). "Tribo-mechanical behavior of HDPE/Natural fibers filler composite materials," MRS Advan. 3(63), 3775-3781. DOI: 10.1557/adv.2018.644

Luedtke, J., Gaugler, M., Grigsby, W. J., and Krause, A. (2019). "Understanding the development of interfacial bonding within PLA/wood-based thermoplastic sandwich composites," Indust. Crops Prod. 127, 129-134. DOI: 10.1016/j.indcrop.2018.10.069

Migneault, S., Koubaa, A., Perre, P., and Riedl, B. (2015). "Effects of wood fiber surface chemistry on strength of wood-plastic composites," Appl. Surface Sci. 343, 11-18. DOI: $10.1016 /$ j.apsusc.2015.03.010

Mohit, H., and Selvan, V. A. M. (2018). "A comprehensive review on surface modification, structure interface and bonding mechanism of plant cellulose fiber reinforced polymer based composites," Composite Interfaces 25(5-7), 629-667. DOI: $10.1080 / 09276440.2018 .1444832$

Mokhena, T. C., and Luyt, A. S. (2014). "Investigation of polyethylene/sisal whiskers nanocomposites prepared under different conditions," Polym. Composites 35(11), 2221-2233. DOI: $10.1002 / p c .22887$

Moon, R. J., Martini, A., Nairn, J., Simonsen, J., and Youngblood, J. (2011). “Cellulose nanomaterials review: Structure, properties and nanocomposites," Chem. Soc. Rev. 40(7), 3941-3994. DOI: 10.1039/c0cs00108b

Mu, B. S., Wang, H. G., Hao, X. L., Wang, Q. W. (2018). “Morphology, mechanical properties and dimensional stability of biomass particles/high density polyethylene composites: Effect of species and composition," Polymers 10(3), article no. 308. DOI: $10.3390 /$ polym 10030308 
Mulinari, D. R., Voorwald, H. J. C., Cioffi, M. O. H., Rocha, G. J., and Da Silva, M. L. C. P. (2010). "Surface modification of sugarcane bagasse cellulose and its effect on mechanical and water absorption properties of sugarcane bagasse cellulose HDPE composites," BioResources 5(2), 661-671.

Najafi, S. K. (2013). "Use of recycled plastics in wood plastic composites - A review," Waste Management 33(9), 1898-1905. DOI: 10.1016/j.wasman.2013.05.017

Najafi, A., and Khademi-Eslam, H. (2011). "Lignocellulosic filler/recycled HDPE composites: Effect of filler type on physical and flexural properties," BioResources 6(3), 2411-2424.

Nair, S. S., Dartiailh, C., Levin, D. B., and Yan, N. (2019). "Highly toughened and transparent biobased epoxy composites reinforced with cellulose nanofibrils," Polymers 11(4), article no. 612. DOI: 10.3390/polym11040612

Neelamana, I. K., Thomas, S., and Parameswaranpillai, J. (2013). "Characteristics of banana fibers and banana fiber reinforced phenol formaldehyde compositesmacroscale to nanoscale," J. Appl. Polym. Sci. 130(2), 1239-1246. DOI: 10.1002/app.39220

Neves, R. M., Lopes, K. S., Zimmermann, M. V. G., Poletto, M., and Zattera, A. J. (2019). "Characterization of polystyrene nanocomposites and expanded nanocomposites reinforced with cellulose nanofibers and nanocrystals," Cellulose 26(7), 4417-4429. DOI: 10.1007/s10570-019-02392-2

Newman, R. H., Hebert, P., Dickson, A. R., Even, D., Fernyhough, A., and Sandquist, D. (2014). "Micromechanical modelling for wood-fibre reinforced plastics in which the fibres are neither stiff nor rod-like," Composites Part A - Appl. Sci. Manufac. 65, $57-$ 63. DOI: 10.1016/j.compositesa.2014.05.012

Nishitani, Y., Mukaida, J., Yamanaka, T., Kajiyama, T., and Kitano, T. (2016). "Influence of initial fiber length on the mechanical and tribological properties of hemp fiber reinforced plants-derived polyamide 1010 biomass composites," Proceedings of PPS-32: The $32^{\text {nd }}$ International Conference of the Polymer Processing Society, A. Maazouz (ed.), Book Series: AIP Conference Proceedings, Vol. 1914, article number: UNSP 070003. DOI: 10.1063/1.5016730

Novo, L. P., Curvelo, A. A. D., and Carvalho, A. J. F. (2018). "Nanocomposites of acid free CNC and HDPE: Dispersion from solvent fat driven by fast crystallization/gelation," J. Molec. Liquids 266, 233-241. DOI: 10.1016/j.molliq.2018.06.062

Ogah, A. O., and Afiukwa, J. N. (2014). "Characterization and comparison of mechanical behavior of agro fiber-filled high-density polyethylene bio-composites," J. Reinforc. Plast. Composites 33(1), 37-46. DOI: 10.1177/0731684413509425

Ouzas, A., Niinivaara, E., Cranston, E. D., and Dube, M. A. (2019). "Synthesis of poly(isobutyl acrylate/n-butyl acrylate/methyl methacrylate)/CNC nanocomposites for adhesive applications via in situ semi-batch emulsion polymerization," Polym. Composites 40(4), 1365-1377. DOI: 10.1002/pc.24869

Ozmen, N., Cetin, N. S., Mengeloglu, F., and Birinci, E. (2013). "Vinyl acetate modified scots pine reinforced HDPE composites: Influence of various levels of modification on mechanical and thermal properties," BioResources 8(1), 1361-1373. DOI: 10.15376/biores.8.1.1361-1373

Peng, Y. C., Gardner, D. J., and Han, Y. (2015). "Characterization of mechanical and morphological properties of cellulose reinforced polyamide 6 composites," Cellulose 22(5), 3199-3215. DOI: 10.1007/s10570-015-0723-y 
Pereira, C., Pisanu, L., Viana, J., Azevedo, J., Almeida, T., Fook, M., Wellen, R., and Canedo, E. (2019). "Heterophasic polypropylene and wood flour composites: Processing and properties," Mater. Res. Express 6(8), article no. 085321. DOI: 10.1088/2053-1591/ab1fc6

Peresin, M. S., Zoppe, J. O., Vallejos, M. E., Habibi, Y., Hubbe, M. A., and Rojas, O. J. (2013). "Nano- and microfiber composites reinforced with cellulose nanocrystals," in: Cellulose Based Composites: New Green Nanomaterials, Hinestroza, J., and Netravali, A. N. (eds.), Wiley-VCH, New York, 77-113.

Peric, M., Putz, R., and Paulik, C. (2019). "Influence of nanofibrillated cellulose on the mechanical and thermal properties of poly(lactic acid)," Eur. Polym. J. 114, 426-433. DOI: 10.1016/j.eurpolymj.2019.03.014

Petchwattana, N., Covavisaruch, S., and Chanakul, S. (2012). "Mechanical properties, thermal degradation and natural weathering of high density polyethylene/rice hull composites compatibilized with maleic anhydride grafted polyethylene," J. Polym Res. 19(7), article no. 9921. DOI: 10.1007/s10965-012-9921-6

Phillips, L. N. (1976). “The hybrid effect - Does it exist?” Composites 7(1), 7-8.

Pizzi, A. (2018). "Biosourced thermosets for lignocellulosic composites," in: Thermoset Composites: Preparation, Properties and Applications, A. Khan, S. A. Bhawani, A. M. Asiri, and I. Khan (eds.), Book series: Materials Research Foundations, Vol 30, pp. 81-111.

Pollanen, M., Suvanto, M., and Pakkanen, T. T. (2013). “Cellulose reinforced high density polyethylene composites - Morphology, mechanical and thermal expansion properties," Composites Sci. Technol. 76, 21-28. DOI:

10.1016/j.compscitech.2012.12.013

Puglia, D., Fortunati, E., Santulli, C., and Kenny, J. M. (2015). "Multifunctional ternary polymeric nanocomposites based on cellulosic nanoreinforcements," in: Nanocellulose Polymer Nanocomposites: Fundamentals and Applications, V. K. Thakur (ed.), Book Ser.: Polymer Science and Plastics Engineering, Scrivner, pp. 163-198.

Qiang, T., Wang, J. W., Wolcott, M. P. (2018). "Facile preparation of cellulose/polylactide composite materials with tunable mechanical properties," Polymer-Plastics Technol. Eng. 57(13), 1288-1295. DOI: 10.1080/03602559.2017.1381243

Rahman, K. S., Islam, M. N., Ratul, S. B., Dana, N. H., Musa, S. M., and Hannan, M. O. (2018). "Properties of flat-pressed wood plastic composites as a function of particle size and mixing ratio," J. Wood Sci. 64(3), 279-286. DOI: 10.1007/s10086-018-17023

Raj, R. G., and Kokta, B. V. (1991). "Composites of silane treated cellulosic fibers and high-density polyethylene," Angew. Makromol. Chem. 189, 169-182. DOI: 10.1002/apmc.1991.051890116

Ramamoorthy, S. K., Skrifvars, M., and Persson, A. (2015). "A review of natural fibers used in biocomposites: plant, animal and regenerated cellulose fibers," Polym. Rev. 55(1), 107-162. DOI: 10.1080/15583724.2014.971124

Ramesh, M. (2019). "Flax (Linum usitatissimum L.) fibre reinforced polymer composite materials: A review on preparation, properties and prospects," Prog. Mater. Sci. 102, 109-166. DOI: 10.1016/j.pmatsci.2018.12.004 
Rashno, A., Damabi, R. M., Niaraki, P. R., and Ahmadi, S. (2018). "A new amino silane coupling agent for old corrugated container fibers/high density polyethylene composites," Polymer Compos. 39(6), 2054-2064. DOI: 10.1002/pc.24167

Reddy, M., Mohanty, A. K., and Misra, M. (2010). "Thermoplastics from soy protein: A review on processing, blends and composites," J. Biobased Mater. Bioenergy 4(4), 298-316. DOI: 10.1166/jbmb.2010.1112

Ren, W. H., Zhang, D., Wang, G., and Cheng, H. T. (2014). "Mechanical and thermal properties of bamboo pulp fiber reinforced polyethylene composites," BioResources 9(3), 4117-4127. DOI: 10.15376/biores.9.3.4117-4127

Rong, M. Z., Zhang, M. Q., Liu, Y., Yang, G. C., and Zeng, H. M. (2001). "The effect of fiber treatment on the mechanical properties of unidirectional sisal-reinforced epoxy composites," Composites Sci. Technol. 61(10), 1437-1447. DOI: 10.1016/S02663538(01)00046-X

Roumeli, E., Terzopoulou, Z., Pavlidou, E., Chrissafis, K., Papadopoulou, E., Athanasiadou, E., Triantafyllidis, K., and Bikiaris, D. N. (2015). "Effect of maleic anhydride on the mechanical and thermal properties of hemp/high-density polyethylene green composites," J. Thermal Anal. Calorim. 121(1), 93-105. DOI: 10.1007/s10973-015-4596-y

Ryu, J. H., Han, N. K., Lee, J. S., and Jeong, Y. G. (2019). "Microstructure, thermal and mechanical properties of composite films based on carboxymethylated nanocellulose and polyacrylamide," Carbohydr. Polym. 211, 84-90. DOI: 10.1016/j.carbpol.2019.01.109

Saikia, A., Debbarma, N., and Karak, N. (2019). "Renewable resource based hyperbranched epoxy thermosetting nanocomposite with cellulose nanofiber as a sustainable material," Cellulose 26(8), 4743-4755. DOI: 10.1007/s10570-019-024438

Sakakibara, K., Moriki, Y., Yano, H., and Tsujii, Y. (2017). "Strategy for the improvement of the mechanical properties of cellulose nanofiber-reinforced highdensity polyethylene nanocomposites using diblock copolymer dispersants," ACS Appl. Mater. Interfaces 9(50), 44079-44087. DOI: 10.1021/acsami.7b13963

Sakakibara, K., Yano, H., and Tsujii, Y. (2016). "Surface engineering of cellulose nanofiber by adsorption of diblock copolymer dispersant for green nanocomposite materials," ACS Appl. Mater. Interfaces 8(37), 24893-24900. DOI: 10.1021/acsami.6b07769

Sakurada, I., Nukushina, Y., and Ito, T. (1962). "Experimental determination of elastic modulus of crystalline regions in oriented polymers," J. Polym. Sci. 57(165), 651660. DOI: 10.1002/pol.1962.1205716551

Samir, M. A. S. A., Alloin, F., and Dufresne, A (2005). "Review of recent research into cellulosic whiskers, their properties and their application in nanocomposite field," Biomacromol. 6(2), 612-626. DOI: 10.1021/bm0493685

Sapkota, J., Shirole, A., Foster, E. J., Garcia, J. C. M., Lattuada, M., and Weder, C. (2017). "Polymer nanocomposites with nanorods having different length distributions," Polymer 110, 284-291. DOI: 10.1016/j.polymer.2016.12.010

Sathre, R., and O'Connor, J. (2010). "Meta-analysis of greenhouse gas displacement factors of wood product substitution," Environ. Sci. Policy 13(2), 104-114. DOI: 10.1016/j.envsci.2009.12.005

Schirp, A., Mannheim, M., and Plinke, B. (2014). "Influence of refiner fibre quality and fibre modification treatments on properties of injection-moulded beech wood-plastic 
composites," Composites Part A - Appl. Sci. Manufac. 61, 245-257. DOI:

10.1016/j.compositesa.2014.03.003

Sewda, K., and Maiti, S. N. (2010). "Crystallization and melting behavior of HDPE in HDPE/teak wood flour composites and their correlation with mechanical properties," J. Appl. Polymer Sci. 118(4), 2264-2275. DOI: 10.1002/app.30551

Sheng, C. K., Amin, K. A. M., Kee, K. B., Hassan, M. F., and Ali, E. G. E. (2017). "Effect of wood flour content on the optical color, surface chemistry, mechanical and morphological properties of wood flour/recycled high density polyethylene (rHDPE) composite," $3^{\text {rd }}$ International Conference on the Science and Engineering of Materials (ICOSEM 2017), H. Metselaar, W. Y. Hoong, R. Mahmoodian, and M. F. Jamaludin (eds.), Book Series: AIP Conference Proceedings, Vol. 1958, article Number: UNSP 020002. DOI: 10.1063/1.5034533

Simao, J. A., Marconcini, J. M., Mattoso, L. H. C., and Sanadi, A. R. (2019). "Effect of SEBS-MA and MAPP as coupling agent on the thermal and mechanical properties in highly filled composites of oil palm fiber/PP," Composite Interfaces 26(8), 699-709.

DOI: 10.1080/09276440.2018.1530916

Siqueira, G., Kokkinis, D., Libanori, R., Hausmann, M. K., Gladman, A. S., Neels, A., Tingaut, P., Zimmermann, T., Lewis, J. A., and Studart, A. R. (2017). "Cellulose nanocrystal inks for 3D printing of textured cellular architectures," Advan. Func. Mater. 27(12), article no. 1604619. DOI: 10.1002/adfm.201604619

Soccalingame, L., Bourmaud, A., Perrin, D., Benezet, J. C., and Bergeret, A. (2015). "Reprocessing of wood flour reinforced polypropylene composites: Impact of particle size and coupling agent on composite and particle properties," Polym. Degrad. Stabil. 113, 72-85. DOI: 10.1016/j.polymdegradstab.2015.01.020

Soykeabkaew, N., Laosat, N., Ngaokla, A., Yodsuwan, N., and Tunkasiri, T. (2012). "Reinforcing potential of micro- and nano-sized fibers in the starch-based biocomposites," Composites Sci. Technol. 72(7), 845-852. DOI: 10.1016/j.compscitech.2012.02.015

Stark, N. M., and Rowlands, R. E. (2003). "Effects of wood fiber characteristics on mechanical properties of wood/polypropylene composites," Wood Fiber Sci. 35(2), 167-174.

Summerscales, J., Dissanayake, N. P. J., Virk, A. S., and Hall, W. (2010). "A review of bast fibres and their composites. Part 1 - Fibres as reinforcements," Composites Part A-Applied Sci. Manufac. 41(10), 1329-1335. DOI:

10.1016/j.compositesa.2010.06.001

Sun, Z. Y. (2018). "Progress in the research and applications of natural fiber-reinforced polymer matrix composites," Sci. Eng. Composite Mater. 25(5), 835-846. DOI: 10.1515/secm-2016-0072

Supaphol, P., and Spruiell, J. R. (2002). "Nonisothermal bulk crystallization of highdensity polyethylene via a modified depolarized light microscopy technique: Further analysis," J. Appl. Polym. Sci. 86(4), 1009-1022. DOI: 10.1002/app.11121

Syed, M. A., Ramaraj, B., Akhtar, S., and Syed, A. A. (2010). "Development of environmentally friendly high-density polyethylene and turmeric spent composites: Physicomechanical, thermal, and morphological studies," J. Appl. Polym. Sci. 118(2), 1204-1210. DOI: 10.1002/app.32330

Taib, R. M., Ramarad, S., Ishak, Z. A. M., and Rozman, H. D. (2010). "Effect of acetylation and MAPE on the properties of steam-exploded acacia mangium fiber- 
HDPE composites," J. Reinf. Plastics Composites 29(3), 431-444. DOI:

10.1177/0731684408098004

Tanpichai, S., and Wootthikanokkhan, J. (2018). "Reinforcing abilities of microfibers and nanofibrillated cellulose in poly(lactic acid) composites," Sci. Eng. Composite Mater. 25(2), 395-401. DOI: 10.1515/secm-2016-0113

Tarrés, Q., Vilaseca, F., Herrera-Franco, P. J., Espinach, F. X., Delgado-Aguilar, M., and; Mutje, P. (2019). "Interface and micromechanical characterization of tensile strength of biobased composites from polypropylene and henequen strands," Indust. Crops Prod. 132, 319-326. DOI: 10.1016/j.indcrop.2019.02.010

Tazi, M., Erchiqui, F., Godard, F., and Kaddami, H. (2014). "Evaluation of mechanical properties and durability performance of HDPE-wood composites," J. Renew. Mater. 2(4), 258-263. DOI: 10.7569/JRM.2014.634120

Thakur, V. K., and Thakur, M. K. (2014). "Processing and characterization of natural cellulose fibers/thermoset polymer composites," Carbohydr. Polym. 109, 102-117. DOI: 10.1016/j.carbpol.2014.03.039

Thumm, A., and Dickson, A. R. (2013). "The influence of fibre length and damage on the mechanical performance of polypropylene/wood pulp composites," Composites Part A-Appl. Sci. Manufac. 46, 45-52. DOI: 10.1016/j.compositesa.2012.10.009

Tian, D. L., Wang, F. F., Yang, Z. J., Niu, X. L., Wu, Q., and Sun, P. C. (2019). "Highperformance polyurethane nanocomposites based on UPy-modified cellulose nanocrystals," Carbohydr. Polymers 219, 191-200. DOI: 10.1016/j.carbpol.2019.05.029

Tisserat, B., Reifschneider, L., Joshee, N., and Finkenstadt, V. L. (2013a). "Properties of high density polyethylene - paulownia wood flour composites via injection molding," BioResources 8(3), 4440-4458. DOI: 10.15376/biores.8.3.4440-4458

Tisserat, B., Reifschneider, L., O'Kuru, R. H., and Finkenstadt, V. L. (2013b). "Mechanical and thermal properties of high density polyethylene - dried distillers grains with solubles composites," BioResources 8(1), 59-75. DOI: 10.15376/biores.8.1.59-75

Tisserat, B., Reifschneider, L., Grewell, D., Srinivasan, G., and O'Kuru, R. H. (2015a). "Properties of dried distillers grains with solubles, paulownia wood, and pine wood reinforced high density polyethylene composites: Effect of maleation, chemical modification, and the mixing of fillers," in: Green Biorenewable Biocomposites: From Knowledge to Industrial Applications, V. K. Thakur and M. R. Kessler, pp. 387-426.

Tisserat, B., Reifschneider, L., Joshee, N., and Finkenstadt, V. L. (2015b). "Evaluation of Paulownia elongata wood polyethylene composites," J. Thermoplast. Composite Mater. 28(9), 1301-1320. DOI: 10.1177/0892705713505856

Tong, J. Y., Royan, N. R. R., Ng, Y. C., Ab Ghani, M. H., and Ahmad, S. (2014). "Study of the mechanical and morphology properties of recycled HDPE composite using rice husk filler," Advan. Mater. Sci. Eng., article no. 938961. DOI: 10.1155/2014/938961

Toupe, J. L., Trokourey, A., and Rodrigue, D. (2014). "Simultaneous optimization of the mechanical properties of postconsumer natural fiber/plastic composites: Phase compatibilization and quality/cost ratio," Polym. Composites 35(4), 730-746. DOI: $10.1002 /$ pc. 22716

Tucker, C. L., and Liang, E. (1999). "Stiffness predictions for unidirectional short-fiber composites: Review and evaluation," Composites Sci. Technol. 59(5), 655-671. DOI: 10.1016/S0266-3538(98)00120-1 
Tufan, M., and Ayrilmis, N. (2016). "Potential use of hazelnut husk in recycled highdensity polyethylene composites," BioResources 11(3), 7476-7489. DOI: 10.15376/biores.11.3.7476-7489

Tyagi, P., Lucia, L. A., Hubbe, M. A., and Pal, L. (2019). "Nanocellulose-based multilayer barrier coatings for gas, oil, and grease resistance," Carbohydrate Polymers 206, 281-288. DOI: 10.1016/j.carbpol.2018.10.114

Verma, D., and Jain, S. (2017). "Effect of natural fibers surface treatment and their reinforcement in thermo-plastic polymer composites: A review," Current Organic Synth. 14(2), 186-199. DOI: 10.2174/1570179413666160921114114

Wang, Q. Q., Zhu, J. Y., Reiner, R. S., Verrill, S. P., Baxa, U., and McNeil, S. E. (2012). "Approaching zero cellulose loss in cellulose nanocrystal (CNC) production: recovery and characterization of cellulosic solid residues (CSR) and CNC," Cellulose 19(6), 2033-2047. DOI: 10.1007/s10570-012-9765-6

Wang, X. Q., Yu, Z. M., and McDonald, A. G. (2019a). "Effect of different reinforcing fillers on properties, interfacial compatibility and weatherability of wood-plastic composites," J. Bionic Eng. 16(2), 337-353. DOI: 10.1007/s42235-019-0029-0

Wang, Z. H., Yao, Z . J., Zhou, J. T., He, M., Jiang, Q., Li, A. M., Li, S. P., Liu, M. Q., Luo, S., and Zhang, D. W. (2019b). "Improvement of polylactic acid film properties through the addition of cellulose nanocrystals isolated from waste cotton cloth," Int. J. Biol. Macromol. 129, 878-886. DOI: 10.1016/j.ijbiomac.2019.02.021

Wechsler, A., and Hiziroglu, S. (2007). "Some of the properties of wood-plastic composites," Building Environ. 42(7), 2637-2644. DOI: 10.1016/j.buildenv.2006.06.018

Wolcott, M. P., Tichy, R. J., and Bender, D. A. (1999). "A technology review of woodplastic composites," in: $33^{\text {rd }}$ International Particleboard/Composite Materials Symposium, Proceedings, pp. 103-111.

Xu, K. M., Tu, D. Y., Chen, T. A., Zhong, T. H., and Lu, J. (2016). "Effects of environmental-friendly modified rubber seed shell on the comprehensive properties of high density polyethylene/rubber seed shell composites," Indust. Crops Prod. 91, 132-141. DOI: 10.1016/j.indcrop.2016.06.036

Xu, S. H., Fang, Y. Q., Yi, S. M., Zhai, X. L., He, J., Song, Y. M., and Wang, Q. W. (2019). "Preparation and characterization of wood-fiber-reinforced polyamide 6polypropylene blend composites," J. Appl. Polym. Sci. 136(18), article no. 47413. DOI: 10.1002/app.47413

Xu, X., Jayaraman, K., Morin, C., and Pecqueux, N. (2008). "Life cycle assessment of wood-fibre-reinforced polypropylene composites," J. Mater. Proc. Technol. 198, 168177. DOI: $10.1016 /$ j.jmatprotec.2007.06.087

Xu, X. Z., Liu, F., Jiang, L., Zhu, J. Y., Haagenson, D., and Wiesenborn, D. P. (2013). "Cellulose nanocrystals vs. cellulose nanofibrils: A comparative study on their microstructures and effects as polymer reinforcing agents," ACS Appl. Mater. Interfaces 5(8), 2999-3009. DOI: 10.1021/am302624t

Xu, W. Y., Wang, X. J., Sandler, N., Willfor, S., and Xu, C. L. (2018). "Threedimensional printing of wood-derived biopolymers: A review focused on biomedical applications," ACS Sustain. Chem. Eng. 6(5), 5663-5680. DOI:

10.1021/acssuschemeng.7b03924

Yang, H. P., Yan, R., Chen, H. P., Lee, D. H., and Zheng, C. G. (2007). 'Characteristics of hemicellulose, cellulose and lignin pyrolysis," Fuel 86(12-13), 1781-1788. DOI: 10.1016/j.fuel.2006.12.013 
Yang, H. S. (2017). "Thermal and dynamic mechanical thermal analysis of lignocellulosic material-filled polyethylene bio-composites," J. Thermal Anal. Calorim. 130(3), 1345-1355. DOI: 10.1007/s10973-017-6572-1

Yao, F., Wu, Q. L., Liu, H. Z., Lei, Y., and Zhou, D. G. (2011). "Rice straw fiber reinforced high density polyethylene composite: Effect of coupled compatibilizating and toughening treatment," J. Appl. Polym. Sci. 119(4), 2214-2222. DOI: 10.1002/app.32946

Yasim-Anuar, T. A. T., Ariffin, H., Norrrahim, M. N. F., Hassan, M. A., Tsukegi, T., and Nishida, H. (2019). "Sustainable one-pot process for the production of cellulose nanofiber and polyethylene / cellulose nanofiber composites," J. Cleaner Prodn. 207, 590-599. DOI: 10.1016/j.jclepro.2018.09.266

Yuan, L., and Chen, Z. B. (2013). "Review: Numerical simulation in wood plastic composite extrusion," in: Frontiers of Manufacturing and Design Science III, W. P. Sung and R. Chen (eds.), Book Series: Applied Mechanics and Materials, Vol. 271272, pp. 163-167. DOI: 10.4028/www.scientific.net/AMM.271-272.163

Zabihzadeh, S. M., Dastoorian, F., and Ebrahimi, G. (2010). "Effect of wood species and coupling agent on mechanical properties of wood flour/HDPE composites," J. Reinf. Plastics Composites 29(8), 1146-1152. DOI: 10.1177/0731684409103078

Zhang, J. F., Wang, H. G., Ou, R. X., and Wang, Q. W. (2018). “The properties of flax fiber reinforced wood flour/high density polyethylene composites," J. Forestry Res. 29(2), 533-540. DOI: 10.1007/s11676-017-0461-0

Zhang, J. L., Li, M. C., Zhang, X. Q., Ren, S. X., Dong, L. L., Lee, S. Y., Cheng, H. N., Lei, T. Z., and Wu, Q. L. (2019a). "Surface modified cellulose nanocrystals for tailoring interfacial miscibility and microphase separation of polymer nanocomposites," Cellulose 26(7), 4301-4312. DOI: 10.1007/s10570-019-02379-z

Zhang, J. L., Zhang, X. Q., Li, M. C., Dong, J., Lee, S., Cheng, H. N., Lei, T. Z., and Wu, Q. L. (2019b). "Cellulose nanocrystal driven microphase separated nanocomposites: Enhanced mechanical performance and nanostructured morphology," Ing. J. Biol. Macromol. 130, 685-694. DOI: 10.1016/j.ijbiomac.2019.02.159

Zhang, W. P., Yao, X., Khanal, S., and Xu, S. A. (2018). "A novel surface treatment for bamboo flour and its effect on the dimensional stability and mechanical properties of high density polyethylene/bamboo flour composites," Construc. Building Mater. 186, 1220-1227. DOI: 10.1016/j.conbuildmat.2018.08.003

Zhang, Y. C., Xue, Y. B., Toghiani, H., Zhang, J. L., and Pittman, C. U. (2009). "Modification of wood flour surfaces by esterification with acid chlorides: Use in HDPE/wood flour composites," Composite Interfaces 16(7-9), 671-686. DOI: 10.1163/092764409X12477420906296

Zhou, Y. H., Fan, M. Z., and Lin, L. Y. (2017). "Investigation of bulk and in situ mechanical properties of coupling agents treated wood plastic composites," Polym. Testing 58, 292-299. DOI: 10.1016/j.polymertesting.2016.12.026

Zimniewska, M., Wladyka-Przbylak, M., and Mankowski, J. (2011). "Cellulosic based fibers, their structure and properties suitable for composite applications," in: Cellulosic Fibers: Bio- and Nano-polymer Composites: Green Chemistry and Technology, S. Kalia, B. S. Kaith, and I. Kaur (eds.), Springer, Berlin, pp. 97-120. DOI: $10.1007 / 978-3-642-17370-7 \_4$ 


\section{APPENDIX}

\section{Calculations to Estimate Specific Surface Area of Cellulose Nanocrystals (CNCs) and Softwood Kraft Fibers}

\section{Cellulose nanocrystals (CNC)}

Assume the dimensions shown in the following figure, and a density of $1.5 \mathrm{~g} / \mathrm{cm}^{3}$.

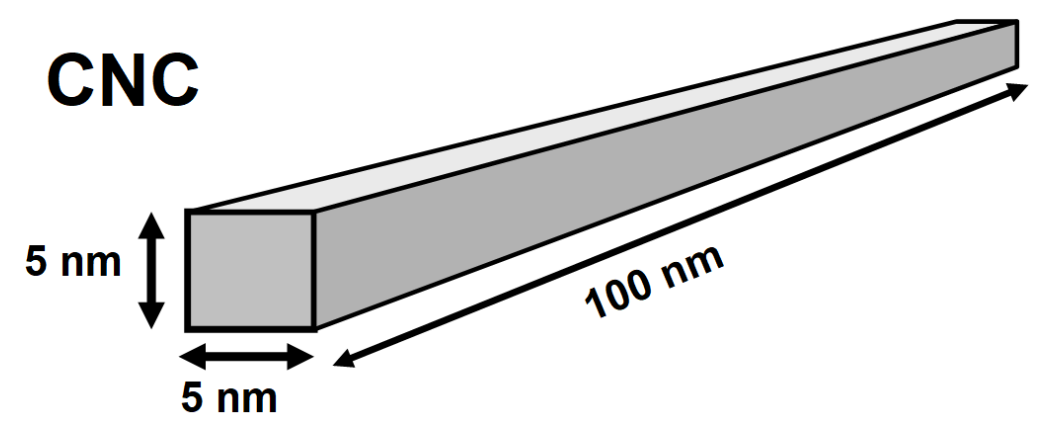

Area of one crystal $\approx 5 \mathrm{nmX} 100 \mathrm{~nm} \mathrm{X} 4=2000 \mathrm{~nm}^{2}=2 \times 10^{-15} \mathrm{~m}^{2}$

Volume of one crystal $=5 \mathrm{~nm} \mathrm{X} 5 \mathrm{~nm} X 100 \mathrm{~nm}=2500 \mathrm{~nm}^{3}=2.5 \times 10^{-18} \mathrm{~cm}^{3}$

Mass of one crystal $=1.5 \mathrm{~g} / \mathrm{cm}^{3} \times 2.4 \times 10^{-18} \mathrm{~cm}^{3}=3.75 \times 10^{-18} \mathrm{~g}$

Area per unit mass $\approx 2 \times 10^{-15} \mathrm{~m}^{2} / 3.75 \times 10^{-18} \mathrm{~g}=533 \mathrm{~m}^{2} / \mathrm{g}$

\section{Softwood fibers}

Assume the dimensions shown in the following figure, and a density of $0.5 \mathrm{~g} / \mathrm{cm}^{3}$.

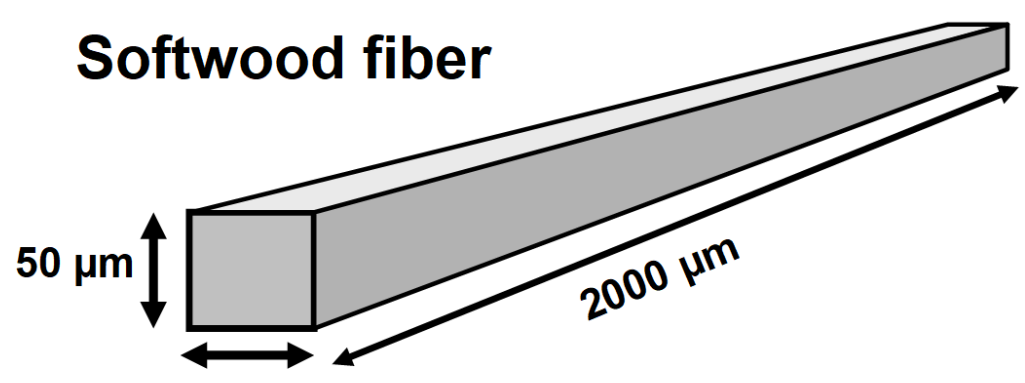

$50 \mu \mathrm{m}$

Area of one fiber $\approx 50 \mu \mathrm{m} \times 2000 \mu \mathrm{m} \mathrm{X} 4=4 \times 10^{5} \mu \mathrm{m}^{2}=4 \times 10^{-7} \mathrm{~m}^{2}$

Volume of one fiber $\approx 50 \mu \mathrm{m} \times 50 \mu \mathrm{m}$ X $2000 \mu \mathrm{m}=5 \times 10^{6} \mu \mathrm{m}^{3}=5 \times 10^{-6} \mathrm{~cm}^{3}$

Mass of one fiber $\approx 0.5 \mathrm{~g} / \mathrm{cm}^{3} \times 5 \times 10^{-6} \mathrm{~cm}^{3}=2.5 \times 10^{-6} \mathrm{~g}$

Area per unit mass $\approx 4 \times 10^{-7} \mathrm{~m}^{2} / 2.5 \times 10^{-6} \mathrm{~g} \approx 1 \mathrm{~m}^{2} / \mathrm{g}$ 
Table A. Relative Strength (Compared to the Corresponding Neat HDPE)

\begin{tabular}{|c|c|c|c|c|c|c|c|c|c|c|c|}
\hline $\begin{array}{l}\text { Matrix } \\
\text { type }\end{array}$ & $\begin{array}{l}\text { Com- } \\
\text { Pat? }\end{array}$ & \multicolumn{2}{|l|}{ Reinforcement ... } & Length & Log & \multicolumn{3}{|c|}{ Tensile Properties ... } & \multicolumn{2}{|c|}{\begin{tabular}{|l|} 
Flexural \\
Properties \\
\end{tabular}} & Reference \\
\hline & & & $(\%)$ & (um) & (Length) & (rel.) & (rel.) & (rel) & (MPa) & $(\mathrm{MPa})$ & \\
\hline HDPE & Yes & Millet husk fiber & 10 & 1000 & 3.00 & 1.10 & 1.40 & 0.02 & 1.18 & 1.11 & Abba et al. 2017 \\
\hline HDPE & No & Pine cone powder & 10 & 1000 & 3.00 & 1.12 & & & 1.26 & 1.25 & Agayev \& Ozdemir 2019 \\
\hline HDPE & No & Kenaf/PALF & 30 & 250 & 2.40 & 0.89 & 1.26 & & 1.00 & 1.15 & Aji et al. 2011 \\
\hline HDPE & No & Kenaf/PALF & 30 & 500 & 2.70 & 0.92 & 1.39 & & 1.10 & 1.25 & Aji et al. 2011 \\
\hline HDPE & No & Kenaf/PALF & 30 & 750 & 2.88 & 0.91 & 1.58 & & 1.20 & 1.50 & Aji et al. 2011 \\
\hline HDPE & No & Kenaf/PALF & 30 & 2000 & 3.30 & 0.92 & 1.52 & & 1.32 & 1.75 & Aji et al. 2011 \\
\hline HDPE & Yes & Teak sawdust & 15 & 150 & 2.18 & 1.00 & & 0.45 & & & Akter et al. 2018 \\
\hline HDPE & No & Date pits & 10 & 500 & 2.70 & 1.05 & & & & & Alsewailem \& B. 2010 \\
\hline HDPE & No & Microfibers & 5 & 634 & 2.80 & 0.70 & 0.50 & & & & Ashok et al. 2019 \\
\hline HDPE & No & Microfibers & 5 & 634 & 2.80 & 0.64 & 0.35 & 1.20 & & & Ashok et al. 2019 \\
\hline HDPE & No & Oak flour & 20 & 325 & 2.51 & 1.00 & 2.00 & & 1.43 & 1.50 & Bajwa et al. 2019 \\
\hline HDPE & No & Three ag wastes & 15 & 50 & 1.70 & 0.70 & 1.11 & 0.44 & 0.80 & 1.24 & Barczewski et al. 2019 \\
\hline HDPE & Yes & Pine fibers & 30 & 200 & 2.30 & 1.41 & 3.27 & & & & Ben Mbarek et al. 2013 \\
\hline HDPE & No & Pine fibers & 30 & 200 & 2.30 & 0.90 & 2.24 & & & & Ben Mbarek et al. 2013 \\
\hline HDPE & Yes & MCC & 10 & 40 & 1.60 & 1.02 & 1.09 & & 1.20 & 1.14 & Boran 2016 \\
\hline HDPE & Yes & Ultrafine cellulose & 4 & 8 & 0.90 & 1.06 & 0.88 & 0.95 & 0.98 & 1.14 & Boran et al. 2016 \\
\hline HDPE & No & Ultrafine cellulose & 4 & 8 & 0.90 & 0.95 & 0.96 & 0.99 & 0.95 & 1.20 & Boran et al. 2016 \\
\hline HDPE & Yes & Wood & 35 & 1200 & 3.08 & 1.22 & 2.24 & & 1.57 & 1.82 & Bouafif et al. 2010 \\
\hline
\end{tabular}




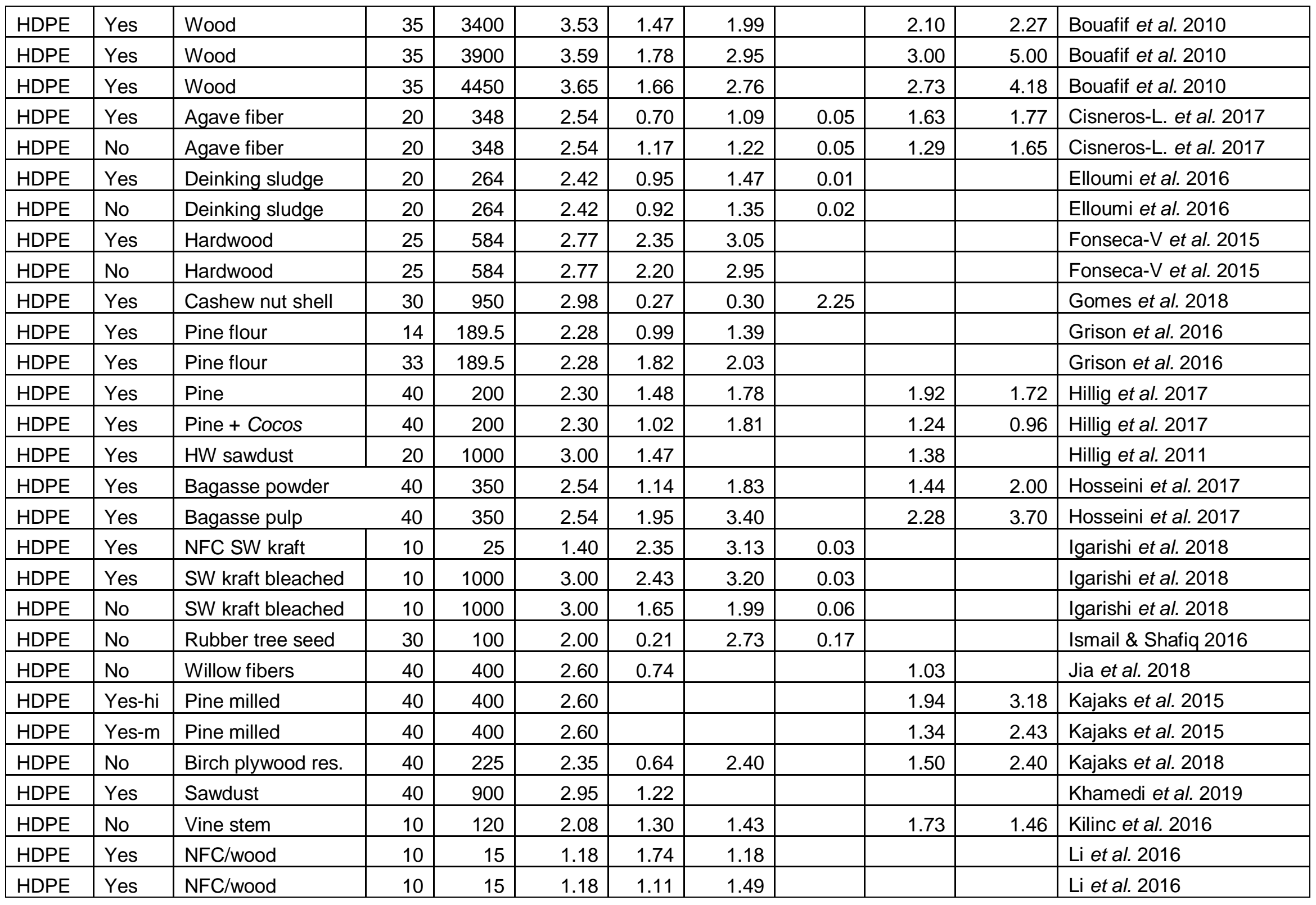




\begin{tabular}{|c|c|c|c|c|c|c|c|c|c|c|c|}
\hline HDPE & Yes & NFC cotton & 30 & 15 & 1.18 & 2.57 & 3.86 & & & & Li et al. 2014 \\
\hline HDPE & Yes & NFC cotton & 30 & 15 & 1.18 & 1.57 & 2.27 & & & & Li et al. 2014 \\
\hline HDPE & Yes & $\mathrm{CNC}$ & 20 & 0.2 & -0.70 & 1.79 & 1.93 & & & & Li et al. 2014 \\
\hline HDPE & No & Peanut shells & 10 & 100 & 2.00 & 0.97 & 1.44 & & & & Louvier-H et al. 2018 \\
\hline HDPE & Yes & Eucalypt kraft & 30 & 53.3 & 1.73 & 1.55 & 3.59 & 0.02 & & & Migneault et al. 2015 \\
\hline HDPE & No & Eucalypt kraft & 30 & 53.3 & 1.73 & 1.66 & 3.33 & 0.02 & & & Migneault et al. 2015 \\
\hline HDPE & No & $\mathrm{CNC}$ & 1 & 0.197 & -0.71 & 1.18 & 1.42 & 0.03 & & & Mokhena \& Luyt 2014 \\
\hline HDPE & Yes & $\mathrm{CNC}$ & 5 & 0.197 & -0.71 & 1.92 & 2.83 & 0.05 & & & Mokhena \& Luyt 2014 \\
\hline HDPE & No & $\mathrm{CNC}$ & 1 & 0.197 & -0.71 & 1.47 & 1.54 & 0.02 & & & Mokhena \& Luyt 2014 \\
\hline HDPE & No & $\mathrm{CNC}$ & 5 & 0.197 & -0.71 & & 1.56 & & & & Mokhena \& Luyt 2014 \\
\hline HDPE & Yes & Cane bagasse & 20 & 350 & 2.54 & 1.33 & 1.78 & 0.73 & & & Mulinari et al. 2010 \\
\hline HDPE & No & Cane bagasse & 20 & 350 & 2.54 & 1.01 & 1.56 & 0.64 & & & Mulinari et al. 2010 \\
\hline HDPE & No & Corn cob fibers & 65 & 150 & 2.18 & & & & 0.64 & 1.47 & Ogah \& Afiukwa 2014 \\
\hline HDPE & No & Rice husk fibers & 65 & 125 & 2.10 & & & & 0.79 & 1.65 & Ogah \& Afiukwa 2014 \\
\hline HDPE & No & Walnut shell & 65 & 165 & 2.22 & & & & 0.50 & 1.12 & Ogah \& Afiukwa 2014 \\
\hline HDPE & No & Flax shive & 65 & 300 & 2.48 & & & & 0.75 & 1.76 & Ogah \& Afiukwa 2014 \\
\hline HDPE & Yes & Pine flour & 30 & 340 & 2.53 & 1.13 & 1.75 & 0.01 & 1.54 & 2.00 & Ozmen et al. 2013 \\
\hline HDPE & Yes & Pine flour & 30 & 340 & 2.53 & 1.23 & 1.64 & 0.01 & 1.75 & 2.25 & Ozmen et al. 2013 \\
\hline HDPE & Yes & Pine flour & 30 & 340 & 2.53 & 1.06 & 1.78 & 0.01 & 1.56 & 2.00 & Ozmen et al. 2013 \\
\hline HDPE & Yes & Pine flour & 30 & 340 & 2.53 & 0.97 & 2.00 & 0.01 & 1.55 & 2.03 & Ozmen et al. 2013 \\
\hline HDPE & No & Pine flour & 30 & 340 & 2.53 & 0.89 & 1.75 & 0.01 & 1.54 & 2.50 & Ozmen et al. 2013 \\
\hline HDPE & Yes & Rice husk & 30 & 75 & 1.88 & 1.39 & & & 1.50 & & Petchwattana et al. 2012 \\
\hline
\end{tabular}




\begin{tabular}{|c|c|c|c|c|c|c|c|c|c|c|c|}
\hline HDPE & No & Rice husk & 30 & 500 & 2.70 & 1.10 & & & 1.18 & & Petchwattana et al. 2012 \\
\hline HDPE & Yes & Viscose fiber & 40 & 6000 & 3.78 & 3.25 & 5.94 & 0.02 & & & Pollanen et al. 2013 \\
\hline HDPE & Yes & MCC & 40 & 100 & 2.00 & 1.63 & 3.64 & 0.03 & & & Pollanen et al. 2013 \\
\hline HDPE & Yes & Aspen CTMP & 30 & 800 & 2.90 & 1.11 & 1.65 & 0.33 & & & Raj \& Kokta 1991 \\
\hline HDPE & No & Aspen CTMP & 30 & 800 & 2.90 & 0.93 & 1.52 & 0.32 & & & Raj \& Kokta 1991 \\
\hline HDPE & Yes & Aspen flour & 30 & 300 & 2.48 & 1.38 & 1.63 & 0.46 & & & Raj \& Kokta 1991 \\
\hline HDPE & No & Aspen flour & 30 & 300 & 2.48 & 0.92 & 1.49 & 0.37 & & & Raj \& Kokta 1991 \\
\hline HDPE & Yes & Bamboo fiber & 30 & 1147 & 3.06 & 1.63 & 3.00 & & 2.05 & 3.14 & Ren et al. 2014 \\
\hline HDPE & Yes & Hemp & 35 & 2000 & 3.30 & 1.11 & 2.04 & 0.00 & & & Roumeli et al. 2015 \\
\hline HDPE & No & Hemp & 35 & 2000 & 3.30 & 0.69 & 1.99 & 0.00 & & & Roumeli et al. 2015 \\
\hline HDPE & Yes & $\mathrm{NFC}$ & 10 & 20 & 1.30 & 1.84 & 2.44 & 0.24 & & & Sakakibara et al. 2016 \\
\hline HDPE & No & NFC & 10 & 20 & 1.30 & 1.37 & 1.81 & 0.49 & & & Sakakibara et al. 2016 \\
\hline HDPE & No & Turmeric spent & 20 & 50 & 1.70 & 0.85 & 1.24 & 0.09 & & & Syed et al. 2010 \\
\hline HDPE & Yes & Acacia fiber & 40 & 800 & 2.90 & 0.74 & 1.73 & 0.23 & & & Taib et al. 2010 \\
\hline HDPE & No & Acacia fiber & 40 & 800 & 2.90 & 0.68 & 1.84 & 0.16 & & & Taib et al. 2010 \\
\hline HDPE & Yes & Spruce sawdust & 30 & 500 & 2.70 & 1.37 & 5.00 & & & & Tazi et al. 2014 \\
\hline HDPE & No & Spruce sawdust & 30 & 500 & 2.70 & 0.74 & 2.67 & & & & Tazi et al. 2014 \\
\hline HDPE & Yes & DDGS & 25 & 300 & 2.48 & 0.94 & 1.08 & 0.15 & & & Tisserat et al. 2013b \\
\hline HDPE & No & DDGS & 25 & 300 & 2.48 & 0.68 & 1.05 & 0.17 & & & Tisserat et al. 2013b \\
\hline HDPE & Yes & Paulownia wood & 25 & 366 & 2.56 & 1.08 & 1.64 & 0.06 & & & Tisserat et al. 2015b \\
\hline HDPE & No & Paulownia wood & 25 & 366 & 2.56 & 0.71 & 1.47 & 0.07 & & & Tisserat et al. 2015b \\
\hline HDPE & Yes & Paulownia wood & 25 & 512 & 2.71 & 0.85 & 1.81 & 0.05 & & & Tisserat et al. 2015b \\
\hline
\end{tabular}




\begin{tabular}{|l|l|l|r|r|r|r|r|r|r|l|l|}
\hline HDPE & Yes & Paulownia wood & 25 & 60 & 1.78 & 1.26 & 1.47 & 0.10 & & Tisserat et al. 2015b \\
\hline HDPE & Yes & Rice husk fibers & 30 & 500 & 2.70 & & 1.45 & & 2.24 & 1.39 & Tong et al. 2014 \\
\hline HDPE & Yes & Douglas fir fiber & 50 & 177 & 2.25 & 1.02 & 3.80 & & & Wang et al. 2019a \\
\hline HDPE & Yes & Rice husk flour & 30 & 163 & 2.21 & & 2.24 & & & Yang 2017 \\
\hline HDPE & No & Rice husk flour & 30 & 163 & 2.21 & & 1.17 & & & Yang 2017 \\
\hline HDPE & Yes & Rice straw & 40 & 1050 & 3.02 & 1.38 & 10.60 & & 1.94 & 2.10 & Yao et al. 2011 \\
\hline HDPE & No & Rice straw & 40 & 1050 & 3.02 & 1.07 & 12.90 & & 1.49 & 3.40 & Yao et al. 2011 \\
\hline HDPE & No & CNF & 5 & 20 & 1.30 & 1.17 & 1.33 & 0.35 & 2.25 & 2.33 & Yasim-Anuar et al. 2019 \\
\hline HDPE & Yes & Pine flour & 35 & 250 & 2.40 & 1.30 & & & & & Zabihzadeh et al. 2010 \\
\hline HDPE & No & Pine flour & 35 & 250 & 2.40 & 1.08 & & & & & Zabihzadeh et al. 2010 \\
\hline HDPE & Yes & Poplar flour & 35 & 250 & 2.40 & 1.35 & & & & & Zabihzadeh et al. 2010 \\
\hline HDPE & No & Poplar flour & 35 & 250 & 2.40 & 1.16 & & & & Zabihzadeh et al. 2010 \\
\hline HDPE & Yes & Pine flour & 20 & 180 & 2.26 & & & & 1.04 & 1.25 & Zhang et al. 2009 \\
\hline
\end{tabular}


Table B. Articles Comparing Different Sizes of Reinforcement Particles in HDPE Matrix

\begin{tabular}{|c|c|c|c|c|c|c|c|c|c|c|c|}
\hline Matrix & Com & Reinforcemer & & & & Properti & es... & & & & References \\
\hline Type & pat? & Type & Level & Length & Log & T. Str. & T. Mod. & & FI. Str. & FI. Mod. & \\
\hline & & & $(\%)$ & (um) & (Len.) & $(\mathrm{MPa})$ & $(\mathrm{MPa})$ & & $(\mathrm{MPa})$ & $(\mathrm{MPa})$ & \\
\hline HDPE & No & Kenaf/PALF & 30 & 250 & 2.40 & 28 & 420 & & & & Aji et al. 2011 \\
\hline HDPE & No & Kenaf/PALF & 30 & 500 & 2.70 & 30 & 465 & & & & Aji et al. 2011 \\
\hline HDPE & No & Kenaf/PALF & 30 & 750 & 2.88 & 29 & 525 & & & & Aji et al. 2011 \\
\hline HDPE & No & Kenaf/PALF & 30 & 2000 & 3.30 & 30 & 510 & & & & Aji et al. 2011 \\
\hline HDPE & Yes & Wood & 35 & 1200 & 3.08 & 21 & 1750 & & 23 & 1040 & Bouafif et al. 2010 \\
\hline HDPE & Yes & Wood & 35 & 3400 & 3.53 & 26 & 1550 & & 31 & 1250 & Bouafif et al. 2010 \\
\hline HDPE & Yes & Wood & 35 & 3900 & 3.59 & 32 & 2300 & & 45 & 2700 & Bouafif et al. 2010 \\
\hline HDPE & Yes & Wood & 35 & 4450 & 3.65 & 30 & 2150 & & 41 & 2300 & Bouafif et al. 2010 \\
\hline HDPE & Yes & Corn fibers & 50 & 87.5 & 1.94 & 23 & 2600 & 1.8 & 34 & 2850 & Chen et al. 2018 \\
\hline HDPE & Yes & Corn fibers & 50 & 154 & 2.19 & 25 & 2800 & 1.8 & 40 & 3500 & Chen et al. 2018 \\
\hline HDPE & Yes & Corn fibers & 50 & 111 & 2.05 & 21.5 & 2650 & 1.7 & 35 & 3150 & Chen et al. 2018 \\
\hline HDPE & Yes & Corn fibers & 50 & 199 & 2.30 & 26.5 & 2400 & 2.3 & 46.5 & 3450 & Chen et al. 2018 \\
\hline HDPE & No & Wood meal & 40 & 400 & 2.60 & & & & 20.7 & 2218 & Chen et al. 2006 \\
\hline HDPE & No & Wood meal & 40 & 665 & 2.82 & & & & 14.8 & 1659 & Chen et al. 2006 \\
\hline HDPE & No & Wood meal & 40 & 960 & 2.98 & & & & 16.4 & 1805 & Chen et al. 2006 \\
\hline HDPE & No & Wood meal & 40 & 2000 & 3.30 & & & & 20.7 & 2218 & Chen et al. 2006 \\
\hline HDPE & Yes & Wood fibers & 40 & 29 & 1.46 & 45 & 1650 & & & & Gallagher \& M. 2013 \\
\hline HDPE & Yes & Wood fibers & 40 & 109 & 2.04 & 46.7 & 1780 & & & & Gallagher \& M. 2013 \\
\hline HDPE & Yes & Wood fibers & 40 & 110 & 2.04 & 49.2 & 2010 & & & & Gallagher \& M. 2013 \\
\hline HDPE & No & Wood fibers & 40 & 29 & 1.46 & 35.6 & 1660 & & & & Gallagher \& M. 2013 \\
\hline HDPE & No & Wood fibers & 40 & 109 & 2.04 & 37.7 & 1800 & & & & Gallagher \& M. 2013 \\
\hline HDPE & No & Wood fibers & 40 & 110 & 2.04 & 29.7 & 2020 & & & & Gallagher \& M. 2013 \\
\hline HDPE & No & SW particles & 4 & 2200 & 3.34 & 15 & 2160 & & 36.8 & 2640 & Gozdecki \& W. 2015 \\
\hline
\end{tabular}




\begin{tabular}{|c|c|c|c|c|c|c|c|c|c|c|c|}
\hline HDPE & No & SW particles & 40 & 4600 & 3.66 & 16.6 & 2330 & & 40.6 & 2790 & Gozdecki \& W. 2015 \\
\hline HDPE & No & SW particles & 40 & 12700 & 4.10 & 18.7 & 2590 & & 45.8 & 3150 & Gozdecki \& W. 2015 \\
\hline HDPE & Yes & NFC SW kraft & 10 & 25 & 1.40 & 54 & & 0.03 & & & Igarishi et al. 2018 \\
\hline HDPE & Yes & SW kraft bleach & 10 & 1000 & 3.00 & 44 & & 0.027 & & & Igarishi et al. 2018 \\
\hline HDPE & Yes & NFC cotton & 30 & 15 & 1.18 & 35 & 1650 & & & & Li et al. 2014 \\
\hline HDPE & Yes & $\mathrm{CNC}$ & 20 & 0.2 & -0.70 & 25 & 850 & & & & Li et al. 2014 \\
\hline HDPE & No & Corn cob fibers & 65 & 150 & 2.18 & & & & 0.64 & 1.47 & Ogah \& Afiukwa 2014 \\
\hline HDPE & No & Rice husk fibers & 65 & 125 & 2.10 & & & & 0.79 & 1.65 & Ogah \& Afiukwa 2014 \\
\hline HDPE & No & Walnut shell & 65 & 165 & 2.22 & & & & 0.5 & 1.12 & Ogah \& Afiukwa 2014 \\
\hline HDPE & No & Flax shive & 65 & 300 & 2.48 & & & & 0.75 & 1.76 & Ogah \& Afiukwa 2014 \\
\hline HDPE & Yes & Rice husk & 20 & 75 & 1.88 & 22 & & & 23.8 & & Petchwattana et al. 2012 \\
\hline HDPE & Yes & Rice husk & 20 & 180 & 2.26 & 21.5 & & & 23.5 & & Petchwattana et al. 2012 \\
\hline HDPE & Yes & Rice husk & 20 & 250 & 2.40 & 21 & & & 23.2 & & Petchwattana et al. 2012 \\
\hline HDPE & Yes & Rice husk & 20 & 355 & 2.55 & 20.7 & & & 22.9 & & Petchwattana et al. 2012 \\
\hline HDPE & Yes & Rice husk & 20 & 500 & 2.70 & 20 & & & 22.9 & & Petchwattana et al. 2012 \\
\hline HDPE & Yes & Viscose fiber & 40 & 6000 & 3.78 & 52.4 & 3980 & 0.0175 & & & Pollanen et al. 2013 \\
\hline HDPE & Yes & MCC & 40 & 100 & 2.00 & 26.2 & 2440 & 0.027 & & & Pollanen et al. 2013 \\
\hline HDPE & Yes & Aspen CTMP & 30 & 800 & 2.90 & 27 & 1800 & 0.33 & & & Raj \& Kokta 1991 \\
\hline HDPE & No & Aspen CTMP & 30 & 800 & 2.90 & 23.8 & 1720 & 0.32 & & & Raj \& Kokta 1991 \\
\hline HDPE & Yes & Aspen flour & 30 & 300 & 2.48 & 32 & 1850 & 0.46 & & & Raj \& Kokta 1991 \\
\hline HDPE & No & Aspen flour & 30 & 300 & 2.48 & 23.5 & 1680 & 0.37 & & & Raj \& Kokta 1991 \\
\hline HDPE & Yes & Paulownia wood & 25 & 60 & 1.78 & 20.8 & 228.1 & & & & Tisserat et al. 2015b \\
\hline HDPE & Yes & Paulownia wood & 25 & 90 & 1.95 & 20.6 & 264.5 & & & & Tisserat et al. 2015b \\
\hline HDPE & Yes & Paulownia wood & 25 & 215 & 2.33 & 20.5 & 265.3 & & & & Tisserat et al. 2015b \\
\hline HDPE & Yes & Paulownia wood & 25 & 366 & 2.56 & 16.7 & 267.7 & & & & Tisserat et al. 2015b \\
\hline HDPE & Yes & Paulownia wood & 25 & 512 & 2.71 & 14 & 280.7 & & & & Tisserat et al. 2015b \\
\hline HDPE & Yes & Rubber seed shell & 50 & 137 & 2.14 & 15 & & 5.7 & 26 & 3200 & Xu et al. 2016 \\
\hline HDPE & Yes & Rubber seed shell & 50 & 163 & 2.21 & 16 & & 5 & 23 & 3100 & Xu et al. 2016 \\
\hline HDPE & Yes & Rubber seed shell & 50 & 210 & 2.32 & 16.8 & & 4.6 & 27.3 & 3240 & Xu et al. 2016 \\
\hline
\end{tabular}

